\title{
PKR: A Kinase to Remember
}

\author{
Shunit Gal-Ben-Ari', lliana Barrera'1, Marcelo Ehrlich² and Kobi Rosenblum ${ }^{1,3 *}$ \\ ${ }^{1}$ Laboratory of Molecular and Cellular Mechanisms Underlying Learning and Memory, Sagol Department of Neurobiology, \\ University of Haifa, Haifa, Israel, ${ }^{2}$ Laboratory of Intracellular Trafficking and Signaling, School of Molecular Cell Biology \& \\ Biotechnology, The George S. Wise Faculty of Life Sciences, Tel Aviv University, Tel Aviv, Israel, ${ }^{3}$ Center for Gene \\ Manipulation in the Brain, University of Haifa, Haifa, Israel
}

Aging is a major risk factor for many diseases including metabolic syndrome, cancer, inflammation, and neurodegeneration. Identifying mechanistic common denominators underlying the impact of aging is essential for our fundamental understanding of agerelated diseases and the possibility to propose new ways to fight them. One can define aging biochemically as prolonged metabolic stress, the innate cellular and molecular programs responding to it, and the new stable or unstable state of equilibrium between the two. A candidate to play a role in the process is protein kinase $R(P K R)$, first identified as a cellular protector against viral infection and today known as a major regulator of central cellular processes including mRNA translation, transcriptional control, regulation of apoptosis, and cell proliferation. Prolonged imbalance in PKR activation is both affected by biochemical and metabolic parameters and affects them in turn to create a feedforward loop. Here, we portray the central role of PKR in transferring metabolic information and regulating cellular function with a focus on cancer, inflammation, and brain function. Later, we integrate information from open data sources and discuss

OPEN ACCESS

Edited by: Christian Gonzalez-Billault, Universidad de Chile, Chile

Reviewed by: Constanze I. Seidenbecher, Leibniz Institute for Neurobiology (LG), Germany

Alexandre Henriques, Neuro-Sys, France

*Correspondence: Kobi Rosenblum kobir@psy.haifa.ac.il

Received: 18 September 2018 Accepted: 10 December 2018

Published: 09 January 2019

Citation:

Gal-Ben-Ari S, Barrera I, Ehrlich M and Rosenblum K (2019) PKR: A Kinase to Remember.

Front. Mol. Neurosci. 11:480 doi: 10.3389/fnmol.2018.00480 current knowledge and gaps in the literature about the signaling cascades upstream and downstream of PKR in different cell types and function. Finally, we summarize current major points and biological means to manipulate PKR expression and/or activation and propose PKR as a therapeutic target to shift age/metabolic-dependent undesired steady states.

Keywords: PKR, protein synthesis, learning and memory, signal transduction, metabolic stress, aging, cancer, Alzheimer's disease

\section{INTRODUCTION}

Protein kinase $\mathrm{R}$ (PKR) is a serine-threonine kinase (551 amino acid long) encoded in humans by the EIF2AK2 gene [located on chromosome 2 (Feng et al., 1992)], which plays a major role in central cellular processes such as mRNA translation, transcriptional control, regulation of apoptosis, and proliferation (García et al., 2007). In accordance with such preponderant role, PKR dysregulation (see Figure 1) has been implicated in cancer, neurodegeneration (Segev et al., 2013, 2015; Stern et al., 2013), inflammation, and metabolic disorders (Segev et al., 2016; Garcia-Ortega et al., 2017). This kinase, which is constitutively and ubiquitously expressed in vertebrate cells, is not found in plants, fungi, protists, or invertebrates (Taniuchi et al., 2016). PKR was first cloned in 1990 at the Pasteur Institute (Meurs et al., 1990; Watanabe et al., 2018), and is also known as Protein kinase RNA-activated; and interferon-induced, double-stranded RNA-domain kinase (Hugon et al., 2009). 
The structural composition of PKR consists of an N-terminal double stranded RNA binding domain composed of two tandem repeats of a conserved double stranded RNA binding motif (dsRBM1 and dsRBM2) interspaced by a 23 amino acid linker, and followed by a flexible linker connecting to a C-terminal kinase domain (Meurs et al., 1990). Both dsRBMs are required for the high-affinity interaction with double stranded RNA (dsRNA) (McKenna et al., 2006). The catalytic domain of PKR, where its dimerization takes place, has a typical protein kinase fold formed between its $\beta$-sheet $\mathrm{N}$-terminal lobe and its $\alpha$-helical C-terminal lobe (Dzananovic et al., 2018). However, while the catalytic domain structure is similar to other protein kinases, the interaction of PKR with its best-characterized substrate, the eukaryotic initiation factor $2 \alpha$ (eIF $2 \alpha)$, requires a specific $\alpha$-helix unique to PKR $(\alpha G)$, which is located on the surface of the C-terminal lobe of the kinase domain (Dar et al., 2005).

While the best-described transcriptional motif in the PKR promoter is an IFN-stimulated response element (ISRE), allowing it to be transcribed in response to type I IFN (Kuhen and Samuel, 1997), numerous transcription factors have been identified as binders of the promoter region of the EIF2AK2 gene [e.g., 92 different factors identified by CHIP-Seq assays in the context of the ENCODE project (Rouillard et al., 2016)]. This scenario supports the notion of PKR as an interferon stimulated gene (ISG), while also allowing for the modulation of PKR expression in cellular programs involving the activation of different repertoires of transcription. Activation of PKR results in a number of conformational changes, the most important of which is its homodimerization, based on biochemical and genetic analyses (Dey et al., 2005). As a result of its homodimerization, PKR is autophosphorylated at multiple serine and threonine sites, including Ser242, Thr255, Thr258, Ser83, Thr88, Thr89, Thr90, Thr446, and Thr451 (Taylor et al., 2001). The latter two, namely, the Thr 446 and Thr 451 sites, are consistently phosphorylated during PKR activation, resulting in further stabilization of its homodimerization and increased catalytic activity (Hugon et al., 2009; Watanabe et al., 2018).

Protein kinase $\mathrm{R}$ serves as a central hub for the detection of cellular stress signals and response to them, and is thus expected to be regulated by different stress-response pathways. In accord with this notion, the canonical activator of PKR is doublestranded RNA (an obligatory feature of the replication process of RNA viruses), rendering PKR as a pattern recognition receptor endowed with cell function modulatory abilities. The central role of PKR in mediating anti-viral responses is also evidenced by the high degree of positive selection exhibited by coding sequence, indicative of the arms race against the pathogens it encounters and combats (Elde et al., 2009; Rothenburg et al., 2009; Carpentier et al., 2016). However, PKR can also be activated by other factors, for example, heat shock proteins, growth factors (e.g., PDGF), and heparin (Li et al., 2006). PKR is also activated in response to numerous insults, including non-viral pathogens (bacterial lipopolysaccharide, which activates the toll-like receptor 4 pathway), nutrition or energy excess, cytokines (e.g., TNF- $\alpha$, IL-1, IFN- $\gamma$ ), calcium, reactive oxygen species, irradiation (presumably by inducing DNA damage), mechanical stress, and endoplasmic reticulum stress resulting from the presence of a large quantity of unfolded proteins [caused, e.g., by tunicamycin, arsenite, thapsigargin, or $\mathrm{H}_{2} \mathrm{O}_{2}$, which in turn activate the PKR activator protein (PACT; RAX in mice)] (Gil and Esteban, 2000; García et al., 2007; Hugon et al., 2017; Watanabe et al., 2018). Figure 2 summarizes molecular pathways upstream and downstream of PKR, and Figure 3 presents interaction partners and substrates of PKR.

PKR is one of four kinases that regulate protein synthesis via the eIF2 $\alpha$ pathway. These kinases include, apart from PKR, the (PKR)-like endoplasmic reticulum kinase (PERK); general control non-derepressible 2 kinase (GCN2), and heme-regulated eIF2 $\alpha$ kinase (HRI). All four kinases regulate the phosphorylation of eukaryotic initiation factor 2 on its $\alpha$ subunit (eIF2 $\alpha$ ), a major regulator of the initiation phase of mRNA translation, the rate limiting step of protein synthesis. Phosphorylation of eIF $2 \alpha$ on Ser 51 by any of the four kinases leads to its inhibition and a consequent transient suppression of general protein synthesis, up to its complete blockade, concomitant with translation of mRNAs that encode for antiviral factors and/or mediate the integrated stress response (Hoang et al., 2018). Such blockade of protein synthesis results in the decrease or prevention of viral replication, and may result in apoptosis (García et al., 2007). PKR can also induce apoptosis independently of eIF $2 \alpha$ phosphorylation, by activation of the FADD/caspase-8/caspase3 and caspase-9 APAF pathways (Gil et al., 2002; von Roretz and Gallouzi, 2010).

Both PKR-dependent apoptosis strategies, either with or without blockade of protein synthesis, serve as antiviral responses. Consequently, many viruses have developed mechanisms which prevent the establishment of an anti-viral state, by inhibiting components of the PKR pathway. These mechanisms include viral proteins that serve as inhibitors of PKR, which inhibit it by direct binding of PKR (thereby preventing autophosphorylation; e.g., Hepatitis C virus, Herpes simplex 1, and Kaposi's sarcoma vIRF-2), changing its subcellular localization (e.g., Human and Murine Cytomegalovirus), directing it for degradation (e.g., Rift valley fever virus), or regulating its activity. Regulation of PKR activity is done by expression of proteins that disrupt PKR RNA binding sites by dsRNA sequestration, direct obstruction of these sites (e.g., Vaccinia virus, Influenza virus), or interference with the phosphorylation of eIF2 $\alpha$ (e.g., Human Immunodeficiency Virus 1) (Dzananovic et al., 2018). Specifically, adenovirus and Epstein-Barr virus transcribe dsRNAs with structural elements required for binding the dsRBMs and a stem-loop structure that inhibits PKR autophosphorylation (McKenna et al., 2006; Wahid et al., 2009; Dzananovic et al., 2014).

In addition to its ability to sense dsRNA, primarily of viral origin, PKR is also activated in response to endogenous RNA. Many of these are non-coding RNAs and/or regulatory RNAs such as microRNAs (miRNAs). For example, the noncoding nc886 miRNA functions as a suppressor of PKR by interacting with it directly (Lee et al., 2011), and its expression is increased in some malignancies but reduced others (Lee et al., 2016). In accordance, its suppression or epigenetic silencing result in induction of apoptosis and increased expression of 


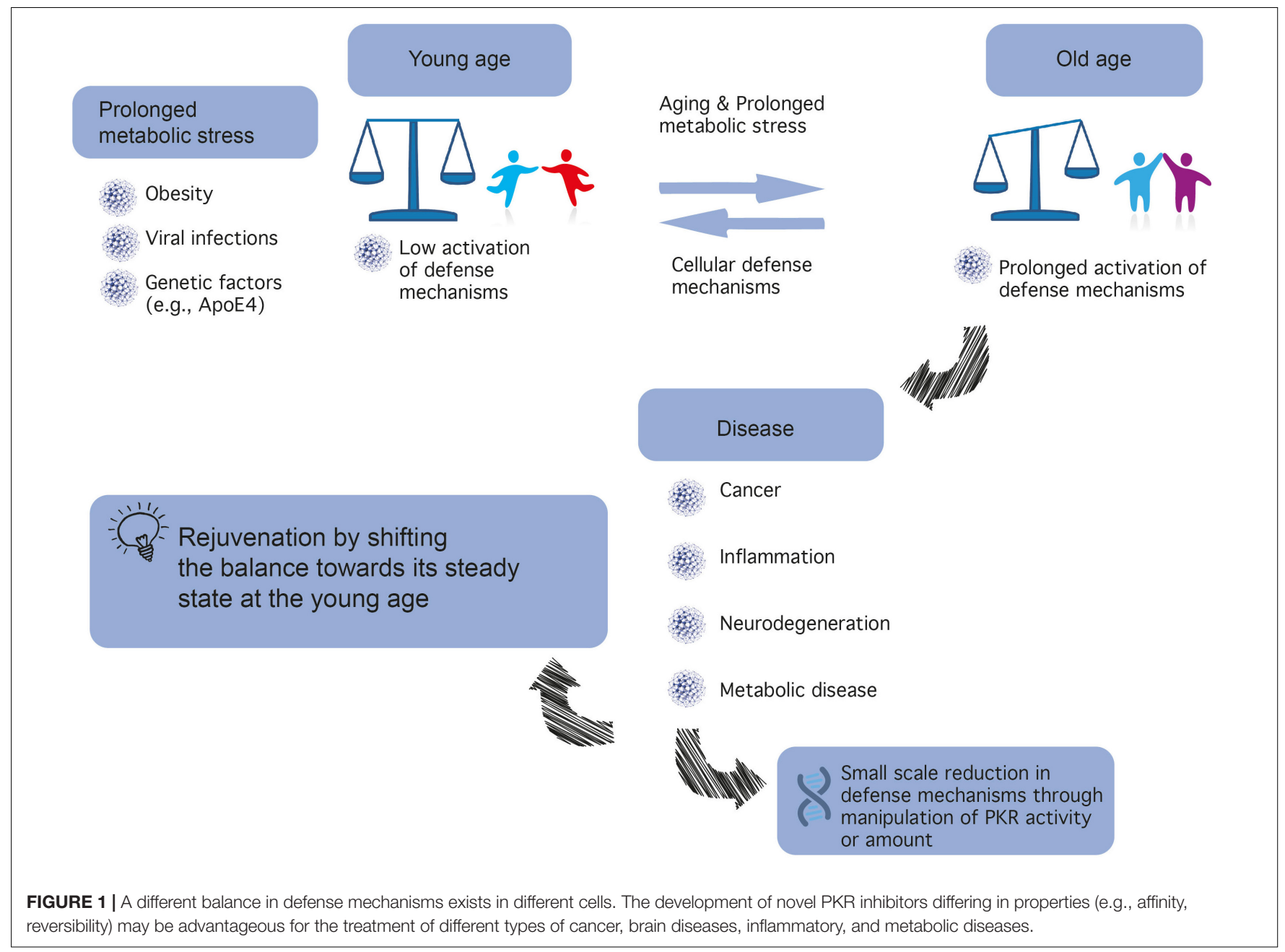

oncogenes in certain models of cancer (Lee et al., 2014; Hu et al., 2017), and a protective effect in other models of cancer in vitro (Lee et al., 2016). Additionally, overexpression of miR-29b in developing cerebellar granular neurons confers protection against ethanol neurotoxicity leading to apoptosis through the SP1/RAX/PKR cascade (Qi et al., 2014). Another example is the long non-coding RNA HOX antisense intergenic RNA (HOTAIR), whose overexpression in keratinocytes resulted in increased expression of PKR and, as a result, decreased cell viability, increased levels of apoptosis, and increased expression of inflammatory factors in ultraviolet B (UVB)treated cells (Liu and Zhang, 2018). Furthermore, a recent study has shown that PKR binds other non-coding RNAs such as retrotransposons, satellite RNAs, and mitochondrial RNAs (which can form intermolecular dsRNAs through bidirectional transcription of the mitochondrial genome). In fact, in a screen for molecules which bind PKR, done using the formaldehydemediated crosslinking and immunoprecipitation sequencing, mitochondrial RNA constituted the majority of endogenous molecules that bind PKR (Kim et al., 2018). In addition, PKR has been proposed to bind dsRNAs formed by inverted Alu repeats (IRAlus), upon disruption of the nuclear membrane in mitosis, leading to the phosphorylation of eIF $2 \alpha$ in this phase of the cell cycle (Kim et al., 2014).

\section{PKR IN THE BRAIN}

\section{Neurodegeneration}

In the past two decades, increased levels of PKR phosphorylation have been detected in the brains of patients with HIV and neurodegenerative diseases such as Alzheimer's disease (AD) (Chang et al., 2002), Parkinson's disease, Huntington's disease (Peel et al., 2001), dementia, and prion disease (Hugon et al., 2009). Furthermore, elevated levels of p-PKR and p-eIF $2 \alpha$ have been observed in several mouse and monkey models of $\mathrm{AD}$, including wild-type mice and cynomolgus monkeys injected with $\mathrm{A} \beta_{1-42}$ oligomers (i.c.v.), APPSwe/PS1DE9 mice, and ApoE4 mice (Lourenco et al., 2013; Segev et al., 2016). In both AD and Huntington's disease, PKR has been implicated as mediating an ER stress-induced cell death (Peel and Bredesen, 2003; Bando et al., 2005), and it is possible that this is also the case regarding other neurological disorders where PKR levels are elevated. In the case of $\mathrm{AD}$, increased staining of phosphorylated 


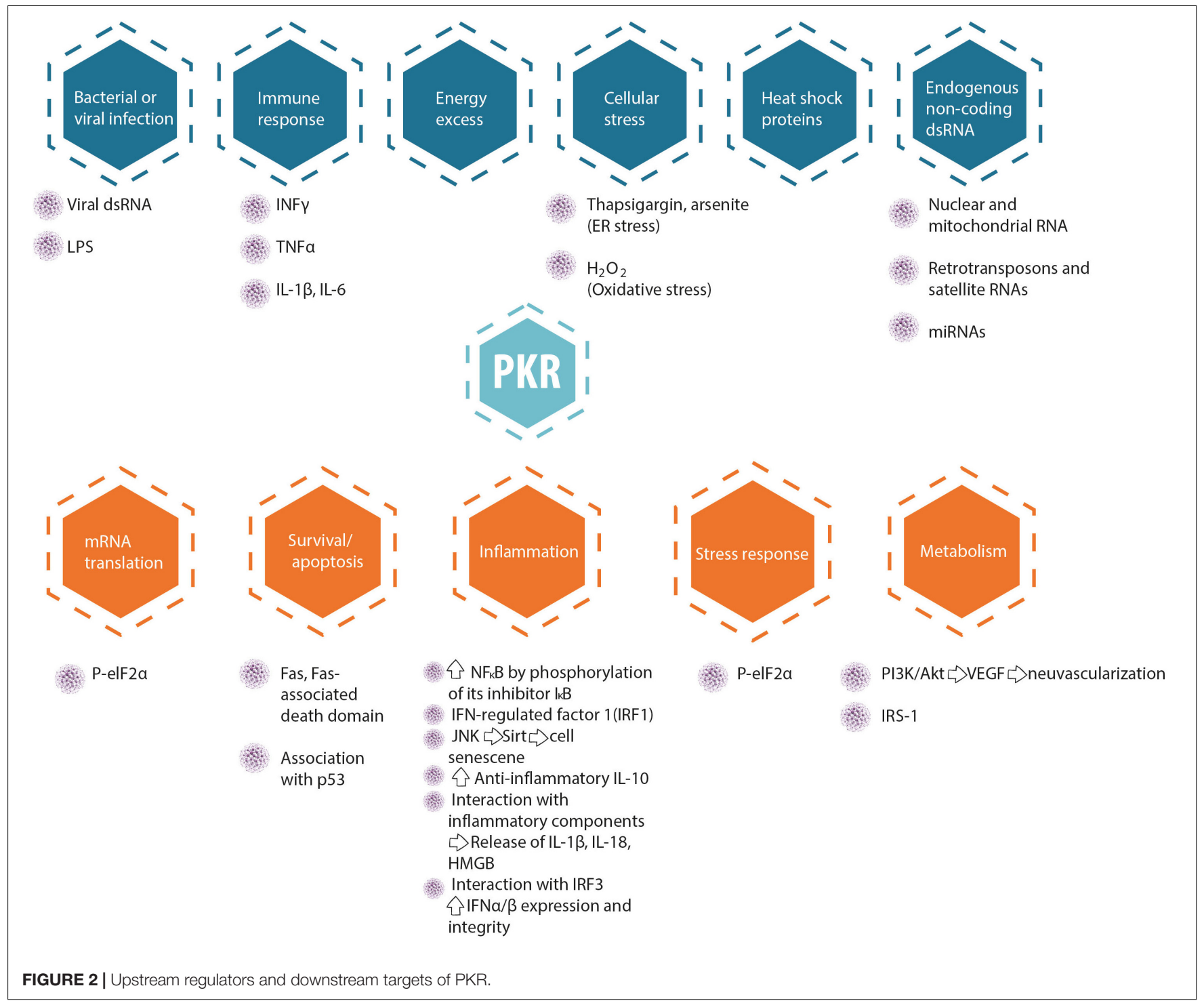

PKR (p-PKR) and phosphorylated eIF2 $\alpha$ (p-eIF2 $\alpha$ ) have been observed mainly in degenerating hippocampal neurons, partially colocalized with hyperphosphorylated tau, a major hallmark of $\mathrm{AD}$, and $\mathrm{p}$-PKR levels are increased in cerebrospinal fluid from patients with $\mathrm{AD}$ and mild cognitive impairment (Mouton-Liger et al., 2012; Hugon et al., 2017), in positive correlation with cognitive decline in $\mathrm{AD}$ (Dumurgier et al., 2013). According to another study, increased levels of p-PKR, p-eIF $2 \alpha$, and p-mTOR were found in peripheral blood lymphocytes derived from $\mathrm{AD}$ patients compared to healthy subjects, in correlation with cognitive decline, further supporting the use of these molecules as biomarkers for the diagnosis of AD progression (Paccalin et al., 2006). Moreover, sporadic cases of AD constitute approximately $95 \%$ of $\mathrm{AD}$ cases, while the rest are familial ones. The sporadic cases are hypothesized to result from interaction between genetic and environmental factors, such as virus infections. Indeed, a study that analyzed human genes involved in the cell response to the herpes simplex virus type 1 (HSV-1) in AD samples compared to healthy subjects identified a SNP (rs2254958) located on the $5^{\prime} \mathrm{UTR}$ region of EIF2AK2, the gene encoding to PKR. This SNP, found within an exonic splicing enhancer, was found to be associated with $\mathrm{AD}$, and homozygous carriers showed slightly earlier onset of $\mathrm{AD}$ (3.3 years), especially in the absence of the APOE4 allele (Bullido et al., 2008).

It has also been shown that in neuroblastoma cells overexpressing $\mathrm{PKR}$, incubation with $\mathrm{A} \beta$ peptide resulted in increased phosphorylation levels of eIF $2 \alpha$, concomitant with an increase in the number of apoptotic cells (Chang et al., 2002). In a reciprocal experiment, incubation of $\mathrm{PKR}^{-/-}$neuroblastoma cells with $\mathrm{A} \beta$ peptide resulted in reduced levels of p-eIF $2 \alpha$ and apoptosis, and in accordance, primary culture cells derived from PKR KO mice were less sensitive to $A \beta$-induced toxicity (Chang et al., 2002). Finally, treatment with C16, the most widely used PKR inhibitor, in 12-month-old 5XFAD AD model mice rescued fear memory deficits almost fully, and restored LTP impairment in these mice. This was shown to occur without affecting $A \beta_{1-42}$ 


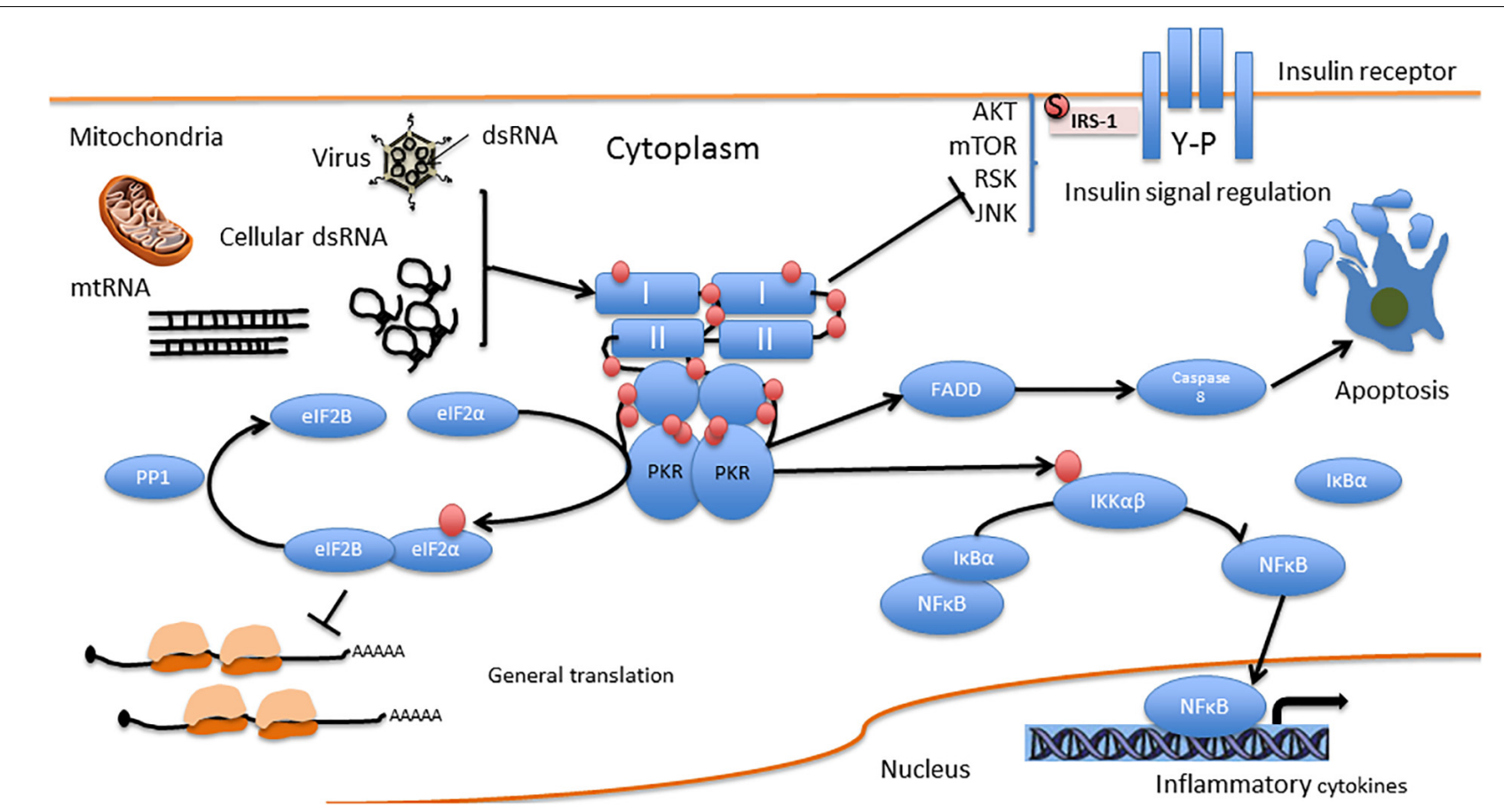

FIGURE 3 | PKR direct interactions. I and II are the dsRNA binding domains. Red circles represent phosphorylation residues.

levels in these mice. Similar cognitive rescue effects were induced by $\mathrm{C} 16$ in $\mathrm{A} \beta_{1-42}$-injected mice in the novel object recognition task and LTP impairment (Hwang et al., 2017).

The link between neurodegenerative diseases and oxidative stress has been a prevailing dogma in neurodegeneration research in the past three decades. Recent studies suggest a link between oxidative stress and PKR. Specifically, the anti-oxidant drug gastrodin (a phenolic glucoside), which suppresses BACE1 expression has been shown to enhance long term memory in the Tg2576 mouse model of AD in the Morris water maze paradigm of spatial learning. While induction of oxidative stress using $\mathrm{H}_{2} \mathrm{O}_{2}$ in neuroblastoma cells led to increased levels of pPKR, p-eIF $2 \alpha$, and BACE1, in accordance with the literature, treatment with either gastrodin or a peptide PKR inhibitor prevented the increased elevation in all three parameters, indicating that gastrodin exerts its neuroprotective effect by inhibition of the PKR/eIF2 $\alpha$ pathway (Zhang et al., 2016). Another study has identified PKR as an inducer of apoptosis in response to oxidative stress. The authors showed that oxidative stress induced by nicotinamide adenine dinucleotide phosphate reduced oxidase (NADPH oxidase; NOX), an enzyme activated downstream of ER-stress, leads to the activation of $\mathrm{PKR}$ and amplification of its downstream target CCAAT/enhancer binding protein homologous protein (CHOP), resulting in apoptosis ( $\mathrm{Li}$ et al., 2010).

\section{Learning and Memory}

Protein kinase $\mathrm{R}$ has also been directly implicated in learning and memory. Cumulative evidence suggests that de novo global protein synthesis is a prerequisite for the consolidation of labile, short-term memory into more stable, long-term memory (Rosenblum et al., 1993; Klann and Richter, 2007; Gkogkas et al., 2010; Alberini and Chen, 2012; Gal-Ben-Ari et al., 2012). Since the rate-limiting step of most protein synthesis through mRNA translation is the initiation phase, it is plausible that global protein synthesis during memory consolidation involves the eIF2 $\alpha$ pathway. Global protein synthesis is increased when phosphorylation levels of eIF $2 \alpha$ are decreased. Indeed, enhancement of long term memory has been shown in both mice and rats, in cortical- and hippocampal-dependent learning paradigms, using genetic and pharmacological methods for decreasing eIF2 $\alpha$ phosphorylation directly or indirectly, by reducing expression levels or activity levels of any of its four regulatory kinases, including PKR. For example, eIF $2 \alpha^{+/ S 51 A}$ mice (where Ser51 is replaced with alanine, preventing the phosphorylation of eIF2 $\alpha$ ) show enhanced performance in hippocampal-dependent spatial memory and contextual and auditory fear conditioning, and cortical-dependent conditioned taste aversion (CTA). The reciprocal experiment of stereotaxic administration of Sal003 (a derivative of salubrinal, which inhibits eIF $2 \alpha$ dephosphorylation) into the rat hippocampus resulted in impaired contextual fear learning (Costa-Mattioli et al., 2007). However, these findings may be ascribed to PERK, rather than PKR, since similar memory enhancement has been observed by PERK genetic reduction (viral vectors and PERK KO mice) or pharmacological inhibition (using PERK inhibitor GSK2606414) (Trinh et al., 2012; Ounallah-Saad et al., 2014; Trinh et al., 2014; Sharma et al., 2018; Zimmermann et al., 2018), and also in a mouse model of AD (Ma et al., 2013; Yang et al., 2016). It is important to note that the main kinase to 
determine the basal phosphorylation state of eIF2 $\alpha$ in the brain and primary culture is PERK (80\%), while the other three eIF2 $\alpha$ kinases including PKR determine the remaining 20\% (OunallahSaad et al., 2014). Below we list findings supporting the beneficial effects of inhibiting or suppressing PKR specifically.

Similarly, in rats, pharmacological inhibition of PKR using C16 (aka PKRi) resulted in enhanced cortical-dependent novel taste learning (insular cortex-dependent positive, incidental learning) and CTA (negative, insular cortex dependent tastemalaise associative learning) when administered either i.p. or stereotaxically into the insular cortex prior to the taste stimulus. Similar results were obtained in mice using these paradigms. This effect of C16 on memory enhancement was shown to be PKR-specific, since it did not occur when $\mathrm{PKR}^{-/-}$mice were administered C16 either in the novel taste learning or the CTA paradigm. However, administration of C16 did not affect phosphorylation levels of eIF2 $\alpha$ either in the hippocampus or the cortex, in WT or PKR KO mice (Jiang et al., 2010; Stern et al., 2013). This point has been neglected in the literature thus far, and is in line with the fact that PERK is the major kinase to determine levels of eIF $2 \alpha$ phosphorylation in the brain (Ounallah-Saad et al., 2014). We deem it important to explicitly state that, contrary to our simplistic view, C16 administration usually does not decrease p-eIF $2 \alpha$ levels either in vivo or in cell culture [e.g., Hwang et al., 2017; 5XFAD mice treated with $\mathrm{A} \beta_{1-42}$ and PKRi $(0.335 \mathrm{mg} / \mathrm{kg}$, i.p.)]. In fact, to the best of our knowledge, in certain cases, p-eIF $2 \alpha$ levels can be decreased by $\mathrm{C} 16$ only by pushing cells to extreme conditions involving massive cell death, such as prolonged incubation with toxic agents and/or high concentrations of $\mathrm{C} 16$ in vivo [e.g., striatal quinolinic acid administration combined with C16 $(600 \mathrm{mg} / \mathrm{Kg}$, i.p.) (Tronel et al., 2014)], ex vivo [e.g., bath treatment of brain slices; C16 (50 $\mu \mathrm{M})$ for $2 \mathrm{~h}$ (Stern et al., 2013)], or in culture [e.g., PKRi $500 \mathrm{nM}$ (C16) in cerebellar granular neurons from rats treated with amprolium $(1.5 \mathrm{mM})$ for $24 \mathrm{~h}$; amprolium is a thiamine competitor and depletes its intracellular levels (Wang et al., 2007); hippocampal neurons treated with $A \beta$ oligomers for $3 \mathrm{~h}$ and PKRi (C16) $1 \mu \mathrm{M}$ (Lourenco et al., 2013)]. C16 has an $\mathrm{IC}_{50}$ of $210 \mathrm{nM}$ (Jammi et al., 2003).

A major current advancement in neuroscience is the ability to zoom in molecularly on specific cell/neuronal types. Zhu et al. (2011) have shown that $\mathrm{PKR}^{-/-}$mice or WT mice treated with PKR inhibitor C16 have enhanced long-term memory and synaptic plasticity in inhibitory neurons, while synaptic plasticity in excitatory neurons is unaltered. Furthermore, the authors demonstrated that IFN- $\gamma$ was increased in $\mathrm{PKR}^{-/-}$mice. In addition, hippocampal-dependent memory enhancement, as measured in the contextual fear conditioning paradigm, was observed following administration of PKR inhibitor C16 and was abolished in IFN- $\gamma^{-/-}$mice. In accordance, treatment of mouse hippocampal slices with C16 led to sustained L-LTP in slices derived from WT mice, but not IFN- $\gamma^{-/-}$mice. The authors concluded that IFN- $\gamma$ mediates disinhibition, which underlies the enhanced cognitive performance and synaptic plasticity when PKR is suppressed genetically or pharmacologically (Zhu et al., 2011). Importantly, the effect downstream of PKR is unclear, since levels of eIF $2 \alpha$ phosphorylation in general or in the relevant
GABAergic neurons were not measured. Further research using neuronal-specific manipulation is needed to better understand the possible differential role of PKR and/or the eIF $2 \alpha$ pathway in different neuronal subtypes.

Other studies have also shown the direct involvement of IFN- $\gamma$ in learning and memory and in synaptic plasticity. For example, the production of IFN- $\gamma$ is altered in many conditions accompanied by cognitive deficits. A recent study has shown that hippocampal-dependent tasks such as spatial memory and recognition memory are enhanced in IFN- $\gamma \mathrm{KO}$ mice (while other functions, such as motor function or anxiety, for example, are unaltered). These IFN- $\gamma \mathrm{KO}$ mice were also shown to have increased DG neurogenesis, along with enlarged dendritic trees, characterized by longer dendrites in this brain subregion, as well as changes in cell volume and number, restricted to the dorsal part of the hippocampus (Monteiro et al., 2016).

\section{PKR IN NEUROINFLAMMATORY PROCESSES}

As mentioned above, PKR is activated by pro-inflammatory cytokines (e.g., TNF- $\alpha$, IL-1, and IFN- $\gamma$ ) (Khandelwal et al., 2011), and in turn, activates inflammation-related pathways, including the pro-apoptotic c-Jun N-terminal kinases (JNK) pathway (Bonnet et al., 2000; De Felice and Ferreira, 2014) and the pro-inflammatory NF- $\kappa \mathrm{B}$ pathway (by direct interaction with I $\mathrm{B}$, an inhibitor of the NF- $\kappa \mathrm{B} \beta$ subunit) (Bonnet et al., 2000). Activated PKR enhances IFN- $\alpha / \beta$ expression by IRF3 activation (Zhang and Samuel, 2008) and contributes to IFN- $\alpha / \beta$ mRNA integrity (Schulz et al., 2010). Activation of both IFN- $\alpha / \beta$ and NF$\kappa \mathrm{B}$ occurs downstream of toll-like receptor 3 (TLR3) activation in response to dsRNA. The signaling cascade, as demonstrated using poly I:C, involves (TLR3)-mediated activation of NF- $\mathrm{B}$ and MAP kinase through the signaling components TLR3-TRAF6TAK1-TAB2-PKR (Jiang et al., 2003). Depending on the cell type and insult activating $\mathrm{PKR}$, it also induces the release of pro-inflammatory IL-1 $\beta$, IL-18, and high mobility group box 1 (HMGB1) protein (Lu et al., 2012). However, in addition to its pro-inflammatory activity, PKR also activates anti-inflammatory IL-10 (Cheung et al., 2005; Chakrabarti et al., 2008) and reduces CD8 T cell proliferation in several models (Grolleau et al., 2000; Kadereit et al., 2000). In addition, PKR promotes apoptosis by interacting with the Fas-associated death domain protein (Couturier et al., 2010; von Roretz and Gallouzi, 2010) and upregulation of the proapoptotic factor Bax (Balachandran et al., 1998).

Indeed, neuroinflammation and activation of microglia are molecular hallmarks of $\mathrm{AD}$, alongside neuronal loss, $\mathrm{A} \beta$ senile plaques (which are surrounded by reactive microglia and astrocytes), and neurofibrillary tangles of hyperphosphorylated tau protein (Duyckaerts et al., 2009). In addition, it has been shown in mice that inflammation, even if external to the brain, may lead to neuroinflammation and increased brain levels of $A \beta$ (Kahn et al., 2012; Krstic et al., 2012), whereas treatment of brainexternal inflammation may halt or even reverse the progression of this neuropathology. Increased brain levels of $A \beta$, in turn, 
may lead to exacerbation of inflammation, since $\mathrm{A} \beta$ peptide can activate microglia and lead to further release of pro-inflammatory cytokines, e.g., TNF- $\alpha$ or IL-1 $\beta$ (Kahn et al., 2012; Krstic et al., 2012; Carret-Rebillat et al., 2015). PKR contributes directly to neurotoxicity by activating pro-apoptotic caspase 3 and caspase 8 , as shown in A $\beta$-treated cells and the APPSLPS1 knock-in mouse model of AD (Couturier et al., 2010).

A recent study has uncovered at least some of the molecular mechanisms underlying PKR-mediated neuroinflammation. In this study, the authors injected lipopolysaccharide (LPS; present in bacteria and used to induce inflammation) intraperitoneally to WT or PKR-KO mice, and measured inflammation-related parameters in the cortex and the hippocampus. These authors showed that many of the inflammation-related parameters were PKR-dependent, since these phenomena were not observed in PKR knockout mice, as opposed to WT mice, including LPSinduced increase in hippocampal neuroinflammation (measured by IBA1, a marker of microglia activation), cytokine release (TNF- $\alpha$ and IL-6), as well as BACE1, A $\beta_{42}$, and phosphorylated STAT3 (BACE1 transcription regulator) protein expression levels (Carret-Rebillat et al., 2015).

In another study using PKR KO mice, 7-week-old mice were challenged with intracranial administration (into the left hemisphere) of the neurovirulent JHM strain of mouse hepatitis virus, JHMV, which induces encephalitis. In this model, too, the increase in brain levels of pro-inflammatory genes observed in WT mice was prevented in PKR KO mice (e.g., Il-6, Ccl5, and Cxcl10) (Kapil et al., 2014). However, no such PKR KO vs. WT mouse differences were observed in the respective proteins encoded by these genes, or IL-1 $\beta$ levels (Taga et al., 2017). By contrast, other inflammation-related genes and their respective proteins were matched in the impaired proinflammatory response in PKR KO mice compared to WT mice, for example, IL-10 and TIMP1. Notably, IFN- $\gamma$ levels (gene and protein) were higher in PKR KO mice compared with WT ones (Kapil et al., 2014). It should be noted that both IL-1 $\beta$ and IL- 6 are upregulated following neuroinflammation, and both cytokines promote disruption of the blood-brain barrier (BBB) and recruitment of lymphocytes (Hopkins and Rothwell, 1995; Erta et al., 2012).

These data suggest that pharmacological inhibition of PKR or its downregulation, e.g., by a virus, may also protect against neuroinflammation and its exacerbation. Indeed, injection of C16 (600 $\mu \mathrm{g} / \mathrm{kg}$, i.p.), the currently most potent PKR inhibitor $\left(\mathrm{IC}_{50}=210 \mathrm{nM}\right.$; Jammi et al., 2003), to a rat model (10 weeks old) of acute inflammation, induced by unilateral stereotaxic administration of quinolinic acid (QA), decreased neuronal loss. Furthermore, it ameliorated neuroinflammation, as demonstrated by reduced levels of pro-inflammatory IL-1 $\beta$ and cleaved caspase 3, a marker of apoptosis and increased levels of anti-inflammatory IL-10 (Lu et al., 2012; Tronel et al., 2014). However, no significant differences were detected in TNF- $\alpha$ or IL-4 in the QA-treated animals following C16 treatment. In another study, treatment with $\mathrm{C} 16(100 \mu \mathrm{g} / \mathrm{kg})$ was shown to prevent neonatal hypoxia-ischemia brain damages by inhibiting neuroinflammation, reducing pro-inflammatory TNF- $\alpha$, IL-6, and IL-1 $\beta$ mRNA expression levels in neonate (7 days old) rats
(Xiao et al., 2016). In both studies, less tissue damage was evident in C16-treated animals (Tronel et al., 2014; Xiao et al., 2016).

\section{THE ROLE OF PKR IN METABOLISM}

\section{PKR in Whole-Body Metabolism}

Evidence suggests that PKR constitutes the link binding metabolic stress, obesity, diabetes, and inflammation, although this is controversial across the literature. PKR is apparently involved in metabolism throughout the body, and increased phosphorylation of eIF $2 \alpha$ is a hallmark of obesity and diabetesrelated insulin resistance (Nakamura et al., 2010, 2014; CarvalhoFilho et al., 2012). Furthermore, in culture, PKR inhibits pancreatic $\beta$-cell proliferation (Song et al., 2015), whereas insulin treatment elevates PKR phosphorylation on tyrosine residues, while inhibiting poly I:C-induced PKR phosphorylation on threonine residues (Swetha and Ramaiah, 2015). Additionally, high glucose impairs insulin signaling by activation of the PKR pathway (Udumula et al., 2017), whereas PKR activation induces insulin resistance in peripheral tissues (Nakamura et al., 2010, 2014; Carvalho-Filho et al., 2012; Carvalho et al., 2013). In a recent study, PKR was shown to interact with TAR RNAbinding protein (TRBP) under conditions of metabolic stress, and that phosphorylation of TRBP results in the activation of $\mathrm{PKR}$, which in turn leads to JNK activation. While overexpression of TRBP in obese mice resulted in exacerbation of glucose metabolism, inhibition of TRBP phosphorylation in the liver had beneficial effects, including improved insulin resistance and glucose metabolism as well as reduced inflammation (Nakamura et al., 2015).

In another study, where PKR KO mice were fed on a high fat diet (HFD), insulin levels were markedly higher compared to PKR KO mice fed on control diet or WT mice fed on either diet. However, no significant differences between WT and PKR KO mice fed on HFD were noted in other parameters measured, such as body weight or glucose levels (Taga et al., 2018). Similar findings were reported by Lancaster et al. (2016) regarding these parameters in HFD-fed PKR KO mice. However, Lancaster and colleagues reported that PKR does have a role in T-lymphocyte recruitment, and PKR KO mice had less T cells in adipose tissue, which was thought to protect them from inflammation. However, this was not the case, and the authors showed that genetic deletion of PKR did not protect these mice against saturated fatty acid-induced inflammation or inflammasome activation. Furthermore, contrary to the studies presented above, injection of poly I:C in order to increase PKR did not result in impaired glucose tolerance (Lancaster et al., 2016).

These contradictory findings may be explained by different transgenic mouse models used. The widely used PKR KO mouse models have a deletion either in the $\mathrm{N}$ terminal or $\mathrm{C}$ terminal of PKR, and cells derived from these models were shown to express truncated forms of PKR (Baltzis et al., 2002), which retain partial functionality, and studies have shown that different domains of PKR are required for its different functions. Indeed, the catalytic domain is necessary for suppression of mRNA translation regulation and induction of inflammation in response 
to excessive consumption of nutrients and energy (Garcia-Ortega et al., 2017); the dsRNA binding domain is required for the activation of PKR by snoRNA under conditions of metabolic stress (Youssef et al., 2015); and the protein binding domain of PKR (but not its dsRNA binding domain) is required for other functions, e.g., as an adaptor protein. For example, a catalytically inactive PKR with intact protein binding was shown to promote $\beta$-cell proliferation via the TRAF2/RIP1/NF- $\kappa$ B/c-Myc pathways (Gao et al., 2015). However, this finding is inconsistent with those reported by Song et al. (2015), where PKR was reported to inhibit $\beta$-cell proliferation through sumoylation-dependent stabilization of P53. Of note, most kinase inhibitor compounds, including inhibitors of PKR, target only the catalytic domain (Garcia-Ortega et al., 2017).

\section{PKR Metabolism in the Brain}

Insulin plays a major role in orchestrating energy availability in the body, as well as in the brain, a high-energy demanding organ (Fernandez and Torres-Alemán, 2012). In recent years, it has become increasingly clear that metabolic dysregulation in the brain underlies cognitive disorders, including $\mathrm{AD}$, now considered type III diabetes (de la Monte and Wands, 2008). Such metabolic dysregulation or metabolic stress may result from aging, particularly when combined with high caloric intake and lack of physical exercise, which may lead to health problems spanning obesity, cardiovascular diseases, and diabetes (see Figure 1).

Metabolic stress also plays a role in $\mathrm{AD}$, inter alia, through the Apolipoprotein E (ApoE) protein, which plays a role in lipid metabolism and transport in the liver and the brain, including clearance of $\mathrm{A} \beta$ peptide from the synapse ( $\mathrm{Li}$ et al., 1988). The ApoE4 $\varepsilon 4$ allele (ApoE4) is currently the best studied risk factor for late-onset, sporadic $\mathrm{AD}$, with a prevalence of $20 \%$ in the general population, compared to $50 \%$ in $\mathrm{AD}$ patients, although estimates vary between different sources (Ward et al., 2012).

A recent study examined the interplay of $\mathrm{PKR}$, metabolic stress, and ApoE4. Following prolonged metabolic stress, induced via HFD (60\% fat for 3 months), higher levels of anxiety behavior were observed in ApoE4 mice compared to control ApoE3 mice fed on the same HFD. Furthermore, maintenance on HFD led to poorer levels of metabolic parameters in ApoE4 compared to ApoE3 mice, resembling diabetes mellitus-like characteristics, manifested as more rapid weight gain, lower serum and plasma insulin levels, and higher serum glucose levels in ApoE4 compared to ApoE3 mice. Furthermore, this HFD protocol led to higher hippocampal levels of $\beta$-site amyloid precursor proteincleaving enzyme1(BACE1) and p-eIF2 $\alpha$ protein expression levels, as well as higher hippocampal levels of ATF4 mRNA in ApoE4 compared to ApoE3 mice (Segev et al., 2016). However, the increase observed in p-eIF2 $\alpha$ protein expression levels may be ascribed to eIF $2 \alpha$ regulatory kinases other than PKR, especially PERK, the predominant kinase to affect p-eIF2 $\alpha$, and the main kinase to respond to ER stress (Ounallah-Saad et al., 2014).

In another study, ApoE4 mice were shown to have poorer long-term memory compared to ApoE3 mice, as measured by freezing in the fear conditioning paradigm. However, a singledose treatment with the PKR inhibitor C16 $(0.335 \mu \mathrm{g} / \mathrm{g}$ body weight, $1 \mathrm{~h}$ before conditioning) resulted in restoration of long term memory in ApoE4 mice, with freezing levels similar to ApoE3 mice in the fear conditioning paradigm. In addition, hippocampal ATF4 mRNA levels were found to be higher in ApoE4 mice compared to ApoE3 mice, whose ATF4 levels were similar to those of C57BL/6 mice. Hippocampal ATF4 mRNA levels were further elevated in aged ApoE3 and ApoE4 mice (12 months old) compared to their younger (4 months old) counterparts. Similar findings were observed in humans, where ATF4 mRNA levels were higher in ApoE4 carriers (67-98 years old) compared to non-carrier age-matched controls (Segev et al., 2015).

While immune system aspects are discussed in the section above, the interplay of PKR, the immune system, and metabolism has been shown in several studies. For example, $A \beta$ oligomers have been shown to remove insulin receptors from the neuronal surface, which in turn leads to activation of c-Jun N-terminal kinase (JNK). This is followed by inhibition of the insulin receptor substrate (IRS-1) and, in cultured hippocampal neurons, this inhibition was shown to be mediated both by JNK/TNF $\alpha$ and PKR (Bomfim et al., 2012). This is supported by the finding that elevated levels of serine phosphorylation of IRS-1 and activated JNK were found in brains of both $\mathrm{AD}$ and diabetes patients (Bomfim et al., 2012). In addition, JNK/TNF $\alpha$ signaling leads to peripheral insulin resistance (Gregor and Hotamisligil, 2011), and this may also be the case in AD. Recent studies have shown that while i.c.v. administration of $A \beta_{1-42}$ oligomers to mice resulted in long term memory impairment, this impairment was prevented both in $\mathrm{PKR}^{-/-}$mice and in $\mathrm{TNFR}^{-/-}$mice, and mice treated with either PKR inhibitor C16 or TNF- $\alpha$ neutralizing antibody, infliximab (Lourenco et al., 2013; Hwang et al., 2017). Furthermore, treatment of hippocampal cultures with insulin prevented $A \beta_{1-42}$ oligomerinduced phosphorylation of PKR (Lourenco et al., 2013).

\section{PKR IN ENDOTHELIAL CELLS}

Protein kinase $\mathrm{R}$ has multiple effects in the vascular system in general and in endothelium cells in particular. One mechanism through which PKR exerts its effect in the vascular system is by modulating the expression of adhesion molecules in endothelial cells in the vascular system, thereby leading to the onset and development of inflammation (Osborn, 1990; Carlos and Harlan, 1994). For example, the adhesion molecule E-selectin is expressed on endothelial cells during inflammation, and its transcription can be induced by TNF- $\alpha$ or IL-1 (Ghersa et al., 1992). The activation of E-selectin by these cytokines is mediated by NF- $\kappa \mathrm{B}$ in conjunction with endothelial leukocyte adhesion molecule 1 (ELAM-1) (Schindler and Baichwal, 1994). In aortic endothelial cells derived from $\mathrm{PKR}^{-/-}$mice, the induction of E-selectin by either TNF- $\alpha$ or PKR-specific inducer was attenuated, supporting the idea described above, that PKR functions downstream of TNF- $\alpha$, and additionally, demonstrating that PKR mediates the role of the adhesion molecule E-selectin in inflammation. Furthermore, the authors showed that the attenuation of E-selectin activation in the PKR deficient mice was caused by a 
reduction in the formation of the NF-ELAM-1 complex, as well as reduced activation of NF- $\mathrm{B}$ (Bandyopadhyay et al., 2000).

As mentioned above, $\mathrm{PKR}$ is activated in response to mechanical stress, and plays a central role in determining cell fate, whether toward apoptosis or survival (Gil and Esteban, 2000; García et al., 2007; Hugon et al., 2017; Watanabe et al., 2018). Furthermore, many of the factors known to promote or exacerbate congestive heart failure, which constitutes mechanical stress due to hemodynamic overload, are also known to activate PKR, including oxidative stress, Toll receptor activation, and lowgrade chronic inflammation (Kadokami et al., 2001; Lu et al., 2010). In a recent study, it was shown that PKR activation is increased both in a model of chronic transverse aortic constriction in mice, a mechanically induced simulation of congestive heart failure, and in human samples of congestive heart failure. Moreover, $\mathrm{PKR}^{-/-}$mice were protected from transverse aortic constriction-induced pulmonary congestion, cardiac dysfunction, elevation in inflammatory cytokines (TNF- $\alpha$ and IL-1 $\beta$ ), and apoptosis (as measured by the TUNEL assay and mRNA and protein expression levels of pro-apoptotic Bax and Caspase-3) (Wang et al., 2014).

Many studies have shown that PKR plays a central role in angiogenesis, which in turn plays a central role in cancer, neurodegeneration, and inflammation, cardiovascular diseases, as well as age-related macular degeneration, a common cause for blindness in the elderly. In two independent studies using in vitro and in vivo models (each) for cardiovascular diseases mediated by hypoxia and mechanical stress caused by hemodynamic pressure, similar results were obtained, showing that PKR is necessary for angiogenesis and neovascularization. Specifically, Zhu et al. (2016) used the RF/6A rhesus choroid-retinal endothelial cell line, where hypoxia was chemically induced using cobalt chloride $\left(\mathrm{CoCl}_{2}\right)$. In this system, PKR expression was upregulated in parallel with $\mathrm{p}$-PI3K, p-Akt, and VEGF expression, all of which were downregulated using siRNA directed against PKR (Zhu et al., 2016). The authors demonstrated that PKR is upstream of p-PI3K, p-Akt, and VEGF using a p-PI3K inhibitor, which affected p-PI3K, p-Akt, and VEGF, but not PKR. In addition, the knockdown of PKR using siRNA in a co-culture of RF/6A and ARPE-19 cells resulted in decreased cell migration and tube formation, strongly implicating the necessity of PKR in the formation of vasculature. In a mouse model of choroidal neovascularization (CNV), which mimics age-related macular degeneration, PKR was colocalized with CD31, a marker of vascular epithelium. In this model, treatment with monoclonal antibodies directed against PKR resulted in decreased progression of CNV. These findings were supported by another study, focusing on peripheral artery disease (Zhu et al., 2015), where $\mathrm{PKR}^{-/-}$mice were shown to have delayed blood flow recovery, with a $34 \%$ decrease in CD31 in the ischemic tissue, indicating a reduced number of endothelial cells. In vitro, the authors demonstrated in a model of human umbilical vein endothelial cells (HUVECs) that pPKR expression was increased in response to hypoxia, whereas inhibition of PKR using siRNA resulted in reduced microtubule formation and migration. Furthermore, VEGF expression was reduced both in $\mathrm{PKR}^{-/-}$mice and in HUVECs treated with $\mathrm{PKR}$
siRNA, supporting the findings of the study above regarding the necessity of PKR for VEGF-mediated angiogenesis under hypoxia conditions.

Other studies have shown the role of PKR in angiogenesis in the context of hypoxia in tumors. For example, PKR was shown to function as a tumor suppressor, downregulating transcription of hypoxia-inducible factor $1 \alpha$ (HIF- $1 \alpha)$ under hypoxia conditions. This was shown to occur by PKR-regulated activation of T-cell protein tyrosine phosphatase, which in turn suppresses signal transducer and activator of transcription 3 (Stat3) (Papadakis et al., 2010). The role of PKR in cancer is discussed in further detail below.

Aging, as a risk factor for cancer, cardiovascular diseases, and neurodegeneration, is also related to senescence of endothelial cells. A recent study has shown that PKR inhibition (either by siRNA for PKR or inhibition of its phosphorylation using 2AP) can reverse palmitate-induced (an independent risk factor of cardiovascular diseases) senescence of HUVECs, by activating JNK. JNK activation results in inhibition of silent information regulator 1 (Sirt1), which serves as an anti-senescent factor (Li et al., 2018), by affecting downstream targets such as histones, transcription factors, and many other aging proteins, one of which is the tumor suppressor p53 (Volonte et al., 2015). Taken together, these studies point to PKR as an attractive target for the treatment of cardiovascular diseases.

\section{PKR IN CANCER}

\section{PKR, an Enzyme With Contentious Roles in Cancer}

While the role of PKR in metabolic stress and brain function is well established and described above, the role of PKR in cancer biology remains a subject of debate, as both tumor-suppressive and tumor-stimulatory functions have been attributed to this enzyme. The attribution of different and even contradictory roles for PKR in tumorigenesis reflect its involvement in the regulation of diverse cellular processes which may differentially affect the cancer cell and its interaction with the tumor microenvironment. Such processes include cell autonomous events such as the negative regulation of protein synthesis through eIF $2 \alpha$ phosphorylation or signal transduction through different pathways including NF- $\kappa \mathrm{B}$, which alter the susceptibility of the cell to apoptosis and modulate the expression of inflammatory cytokines. Thus, variations in PKR expression and activity are predicted to affect both cancer-cell-autonomous and non-cell-autonomous aspects of the developing tumor.

This duality of effects is predicted to be a source of differences in experimental results and in their ensuing interpretation, with dependence on tumor type, tumor stage, or experimental model. Thus, results may differ between in vitro vs. in vivo studies, immune-deficient vs. immunocompetent mouse models, and tumors driven or not by inflammation. Also, the regulatory role performed by $\mathrm{PKR}$ in transduction of oncogenic/tumor suppressor signals may serve as a source for dual roles in tumor progression. This is exemplified by the PKR-mediated activation of NFKB (Maran et al., 1994). PKR was shown to 
activate NF- $\mathrm{B}$ in diverse cellular contexts, with a differential dependence on its enzymatic activity (Kumar et al., 1994; Bonnet et al., 2000; Bonnet et al., 2006). As NF-кB may have powerful, albeit contradictory (double-edged sword) roles in cancer, mediating either tumor promotion or tumor suppression in different tumor settings (Pikarsky and Ben-Neriah, 2006), one can imagine similarly dual roles for PKR. Moreover, the proposed non-enzymatic activity of PKR may support the distinction between pro- or anti-tumorigenic roles, alternatively resulting from modifications in PKR expression or activity. In this context, functional interactions between PKR and protumorigenic signaling pathways [e.g., STAT3 (Shen et al., 2012) or v-mos (Dagon et al., 2001)] were proposed to inhibit PKR activity, resulting in a scenario where increased PKR expression may not necessarily coincide with its increased activity.

\section{Tumor Suppressor Roles of PKR}

The notion that PKR functions as a tumor suppressor is supported by: (i) Cell growth inhibition upon PKR overexpression (Chong et al., 1992; Meurs et al., 1993). In this context, PKR-mediated regulation of cellular replication may occur either through the inhibitory effect of PKR on protein synthesis, an essential resource for cell growth, or through PKR-dependent phosphorylation of cell cycle regulators. Of note, the expression and activity of PKR are differentially regulated in the cell cycle (Zamanian-Daryoush et al., 1999), and exposure to dsRNA upon mitotic breakdown of the nuclear envelope and exposure of dsRNA was proposed as a mechanism for PKR activation in mitosis (Kim et al., 2014). However, both stimulatory (Kim et al., 2014) and inhibitory (Dagon et al., 2001; Yoon et al., 2010) roles have been proposed for PKR in mitotic progression, underscoring the putative dual role of PKR in cancer. (ii) PKR-mediated stimulation of apoptosis through different molecular mechanisms (Jagus et al., 1999; Gil and Esteban, 2000) including transcription- and translationmediated increases in expression of receptors that mediate programmed cell death (e.g., Fas (CD95/Apo-1) and/or proapoptotic Bcl2 effector proteins (Balachandran et al., 1998), which result in increased caspase activity (Gil et al., 2002). (iii) Functional interactions between PKR and tumor suppressors which regulate apoptosis (e.g., p53). Indeed, PKR is a p53 target gene (Yoon et al., 2009). Moreover, Type I interferon increases expression of both p53 (Takaoka et al., 2003) and PKR, and PKR amplifies interferon $\beta$ induction by dsRNA (McAllister et al., 2012). Furthermore, PKR and p53 physically interact, and $\mathrm{PKR}$ positively regulates $\mathrm{p} 53$ transcriptional activity (Cuddihy et al., 1999a,b), while p53 positively regulates gene induction by dsRNA (Hummer et al., 2001). Together, these data suggest that PKR and p53 are intertwined in a positive feedback loop. However, other studies show that dsRNA stimulates p53 degradation (Marques et al., 2005; Baltzis et al., 2007), suggesting a negative feedback loop involving p53 and PKR, and underscoring the complexity of their functional interactions. (iv) In vivo experiments demonstrating an inverse correlation between PKR expression and/or activity and tumorigenicity. For example, knockdown of PKR in HCT116 human colon cancer cells supported rapid tumor growth and resistance to genotoxic drugs in nude mice (Yoon et al., 2009). Similarly, expression of dominant-negative mutants of PKR resulted in malignant transformation of NIH $3 \mathrm{~T} 3$ cells and endowed these cells with the ability to generate tumors in nude mice (Koromilas et al., 1992; Meurs et al., 1993; Barber et al., 1995). (v) Reduced expression and/or activity of PKR in tumors. For example, in head and neck carcinoma, PKR and the proliferation marker PCNA exhibited inversely correlated expression patterns, suggesting a proliferation-inhibitory role for PKR (Haines et al., 1998). Furthermore, in myelodysplastic syndrome (a slow growing form of blood cancer), deletion of chromosome $5 q$, and the ensuing lack of IRF1 expression, lead to reduced PKR expression (Beretta et al., 1996). In addition to reduced expression, inactivation of PKR, similarly to what occurs in cells of patients with B-cell chronic lymphocytic leukemia (Hii et al., 2004), was also suggested to support tumorigenesis.

\section{PKR and Tumor Promotion}

The established roles of inflammation in cancer progression (Coussens and Werb, 2002; Hanahan and Weinberg, 2011), the pro-inflammatory nature of NF- $\mathrm{B}$ signaling and its multiple roles in cancer development (Taniguchi and Karin, 2018), and the identification of PKR as a stimulator of NF- $\kappa \mathrm{B}$ activity (Kumar et al., 1994; Maran et al., 1994; Bonnet et al., 2000, 2006) form a strong rationale for pro-tumorigenic signaling by PKR. Indeed, PKR has been identified as overexpressed and activated in several cancers including hematopoietic malignancies (Basu et al., 1997), breast cancer (Kim et al., 2000), melanoma, and colon cancer (Kim et al., 2002). For example, in melanoma, eIF2 $\alpha$ phosphorylation and the ensuing translation reprogramming were recently described as drivers of phenotypic plasticity, invasiveness and therapeutic resistance in melanoma (Falletta et al., 2017). These studies suggest that eIF $2 \alpha$ kinases, such as PKR, may switch melanoma from a proliferative to an invasive cancer cell, driving metastasis in this manner. Indeed, interference with PKR reduced the growth and metastatic potential of murine melanoma (Delgado André and De Lucca, 2007; André et al., 2014). Moreover, and in accord with a correlation between PKR expression and tumor progression, primary melanomas revealed minimal PKR immunoreactivity, while melanoma lymph node metastases expressed high levels of PKR (Kim et al., 2002).

Recent transcriptomic studies in multiple cancer types (e.g., The Cancer Genome Atlas, TCGA) and their compilation into accessible public databases [e.g., cBio Portal, (Cerami et al., 2012; Gao et al., 2013)] allow for a global assessment of PKR expression in human tumors. The picture that emerges is one in which PKR (EIF2AK2) is broadly expressed across different cancer types, individual patients within a defined cancer type show considerably variable (up to 10-fold) levels of PKR expression (Figure 4A), PKR is rarely mutated, and $5-10 \%$ of patients show overexpression of PKR. Visualization of publically accessible TCGA data with the UCSC Xena browser ${ }^{1}$ shows survival data (Kaplan-Meier curves for overall survival) across multiple cancer types (TCGA PanCanAtlas, 12830 patients). These data revealed

\footnotetext{
${ }^{1}$ https://xenabrowser.net
} 


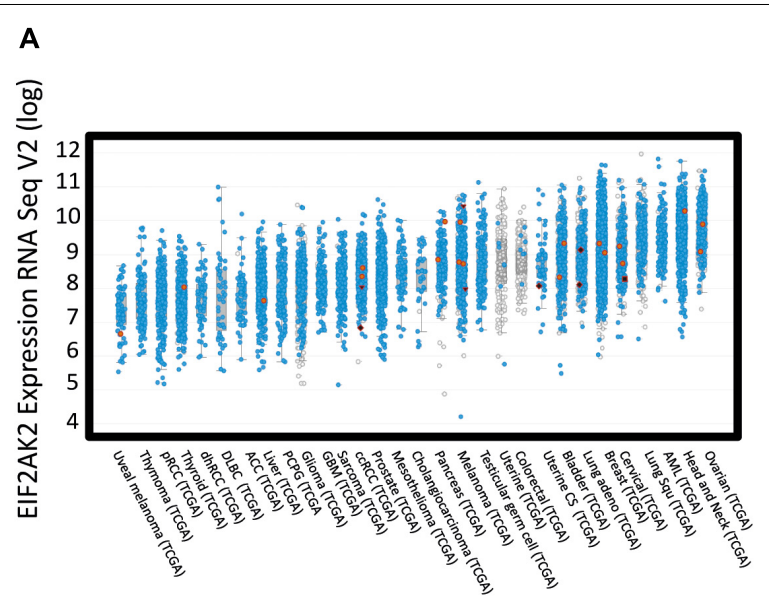

C

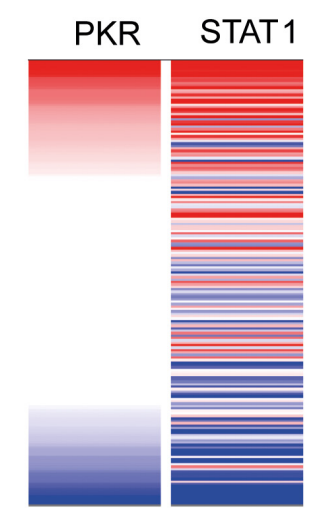

D

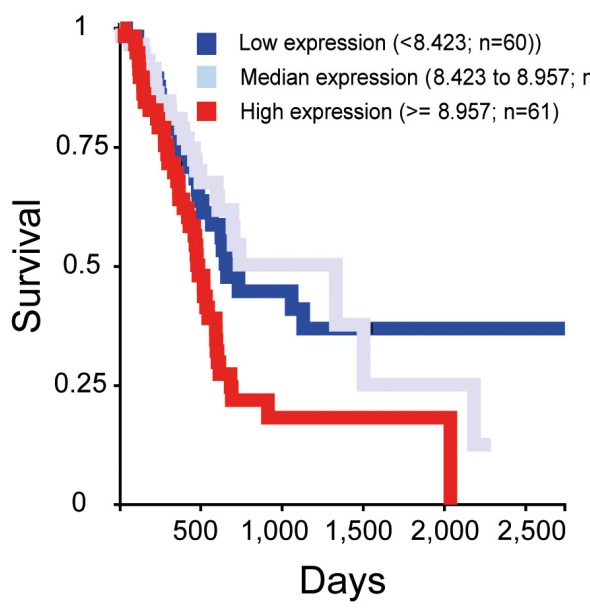

B

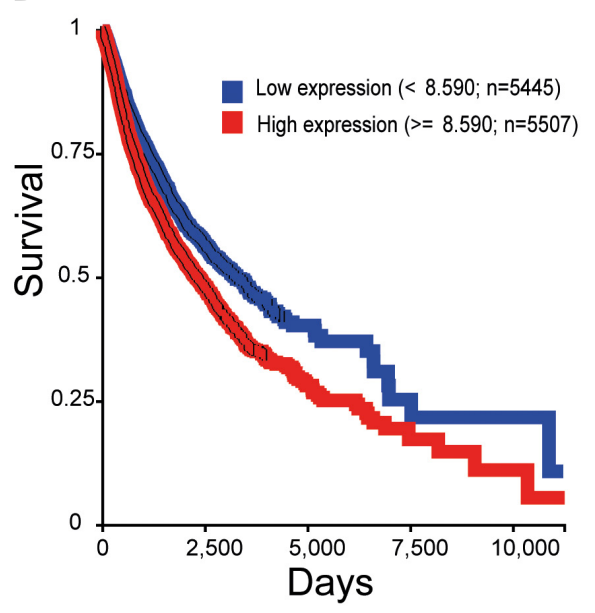

$\mathbf{E}$

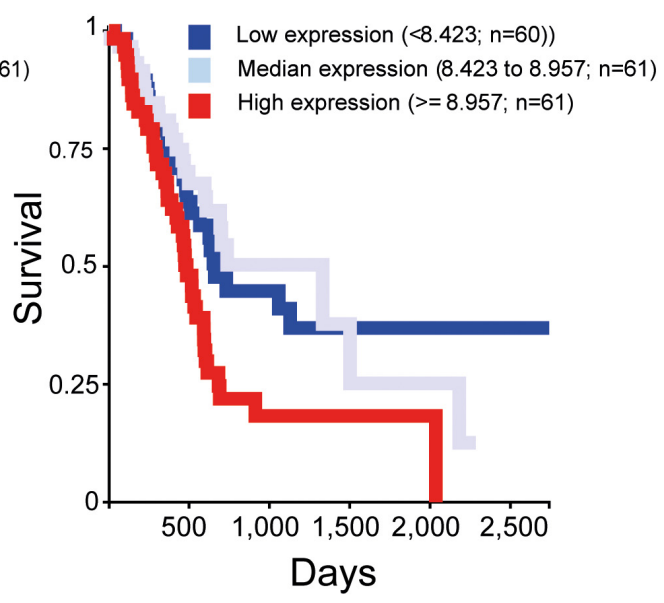

FIGURE 4 | Increased expression of PKR correlates with activation of interferon-STAT1 signaling and with poor prognosis in multiple cancer types. To evaluate the expression of EIF2AK2 (PKR) in samples of cancer patients, we employed cBio Portal to assess studies of The Cancer Genome Atlas (TCGA). (A) Expression of EIF2AK2. Graph depicts the RPKM value of EIF2AK2 expression in different patient samples, ordered according to the median value of expression in the given cancer type. Blue puncta are samples where the EIF2AK2 sequence is wild type, red are samples in which EIF2AK2 is mutated. (B) Analysis of survival of cancer patients according to EIF2AK2 expression. Graph depicts the survival of patients (12830 patients form the PANCAN TGCA database, assessed and visualized with the UCSC Xena browser) classified according to a threshold of EIF2AK2 expression (blue, low expression; red, high expression). (C) Correlation of expression of EIF2AK2 and STAT1 in pancreatic cancer patients (196 cases, PAAD TGCA study, visualized with the UCSC Xena browser). (D,E) Analysis of survival of pancreatic cancer patients according to EIF2AK2 (D) or STAT1 (E) expression. Graph depicts the survival of patients (196 patients form the PAAD TGCA database, assessed and visualized with the UCSC Xena browser) classified according to threshold expression (blue, low expression; gray, median expression; red, high expression).

that higher levels of PKR expression correlated with poor survival (Figure 4B, $p=4.441 \mathrm{E}-16$ ). For example, in pancreatic cancer (PAAD study, TCGA pancreatic cancer database, 196 cases), EIF2AK2 expression is considered as an unfavorable prognostic marker ${ }^{2}$; and data depiction with the UCSC Xena browser shows a negative correlation between PKR expression and survival ( $p=0.001$, Figure 4C). Indeed, expression of STAT1 (an interferon stimulated gene, and a mediator of interferontranscriptional activity) and its correlation with survival in this cohort revealed a similar scenario to the one observed with PKR (Figures 4D,E). Together, these data support the notions of a

${ }^{2}$ https://www.proteinatlas.org pro-tumorigenic association of PKR expression and cancer, and of the regulation of its expression by JAK-STAT signaling in cancer cells. Of note, JAK-STAT signaling pathway is intimately associated with the transduction of signals from inflammatory cytokines (e.g., interferon gamma), suggesting that the protumorigenic role of PKR occurs within the context of tumorrelated inflammation.

PKR in cancer therapy. Due to its roles as a mediator of apoptosis and anti-viral responses, PKR expression and function have been implicated in two forms of anti-cancer therapy: chemotherapy and oncolytic virotherapy. In the former, PKR expression and activity have been positively associated with the therapeutic effects of 5-Fluorouracil [5-FU, (García et al., 2011)], 


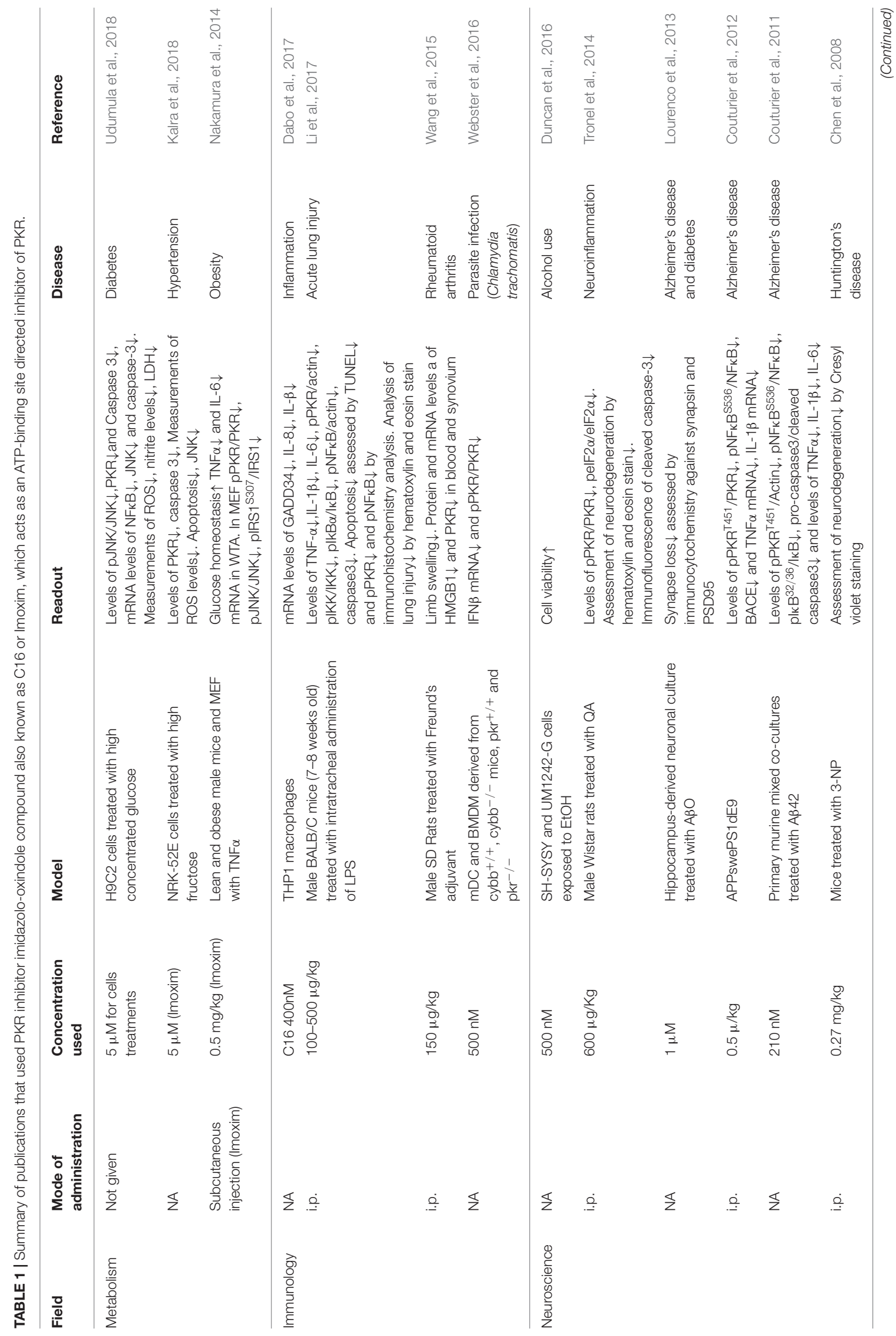


doxorubicin (Peidis et al., 2011), bozepinib (Marchal et al., 2013), and histone deacetylase inhibitors [HDACi, (Peidis et al., 2010)]. Concerning oncolytic virotherapy, which aims at the specific infection and killing of cancer cells (oncolysis) and the activation of anti-tumor immunity, defects in interferon signaling in cancer cells expose these cells to viral oncolysis (Stojdl et al., 2000; Danziger et al., 2016). Specifically, defects in PKR activation were identified as a central mechanism by which oncogenic Ras enables oncolysis of transformed cells with oncolytic reovirus (Strong et al., 1998). In addition to oncolysis resulting from productive infection (a scenario which may benefit from defects in PKR expression or function), we have recently identified a novel form of viral oncolysis (oncolysis by non-productive viral infection, ONPVI) in which the combined exposure of interferon-responsive prostate cancer cells to a novel oncolytic virus (epizootic hemorrhagic disease virus-Tel Aviv University, EHDV-TAU) and interleukin-6, induced caspasemediated cell death. ONPVI occurred in the context of STAT1-dependent upregulation of multiple anti-viral gene products, including PKR (Danziger et al., 2018); opening the possibility that PKR may contribute to virally induced cancer cell death. Given the dependency of anti-immune checkpoint therapy on functional interferon-gamma/JAK-STAT signaling (Zaretsky et al., 2016; Sharma et al., 2017), and the positive feedback loop involving interferon signaling and PKR expression/function, we speculate that PKR may also play roles in this form of therapy. Together, these data suggest that the assessment of the status of PKR expression and function in cancer cells may be important for the choice of optimal therapeutic options, and that the development of means to manipulate its expression and function may have future applications in combination therapy settings.

\section{TOOLS FOR INHIBITING PKR}

Taken together, the studies above point to PKR as a hub for co-morbidity and an attractive target for the treatment of metabolic diseases, cardiovascular diseases, neurodegenerative diseases, inflammation, and cancer. Moreover, when it comes to aging and correlated cognitive decline (Segev et al., 2015), PKR inhibition should serve both as an anti-neurodegenerative disorders agent and a pro-cognitive agent. The main obstacles to better understand PKR are (i) the available tools to inhibit PKR activity in general and specific functions of PKR in particular, (ii) the differences in expression levels between different cells, and (iii) the ability to manipulate PKR in specific cell types within a tissue. The most widely used pharmacological PKR inhibitor is the highly potent small molecule imidazolo-oxindole C16, also known as PKRi, which targets the ATP binding site of PKR. C16 has an $\mathrm{IC}_{50}$ of $210 \mathrm{nM}$ in vitro (Jammi et al., 2003), and is typically used at doses of $210-500 \mathrm{nM}$ in vitro for $1 \mathrm{~h}$ (Table 1). Incubation of cells with high concentrations of C16 induces high cell toxicity (see PKR in Learning and Memory section above). C16 has been successfully used by i.p. administration in mice and rats to elicit memory enhancement, indicating that the compound can cross the blood brain barrier. 
Table 1 shows that inhibition of PKR with C16 rarely inhibits eIF2 $\alpha$ phosphorylation, the most known and cited substrate of PKR. It is clear that, in the brain, PERK is the dominant kinase to control basal levels of eIF2 $\alpha$ phosphorylation (Ounallah-Saad et al., 2014); however, we do not know if this is the case in different neuronal subtypes (e.g., inhibitory versus excitatory neurons). Another less specific pharmacological inhibitor of PKR is the 2-aminopurine (2-AP) compound, which competes for ATP at the ATP binding site of PKR, and thereby inhibits its phosphorylation (Hu and Conway, 1993). This compound is less potent than $\mathrm{C} 16$, and is used in vitro at doses of $4-10 \mathrm{mM}$ for $4 \mathrm{~h}$ (Endoh et al., 2009). Other inhibitors of PKR have been developed, although these were less potent than C16 (Weintraub et al., 2016).

The PKR can also be inhibited by monoclonal antibodies and using genetic tools such as siRNA or viral vectors harboring an shRNA sequence directed against PKR, and both approaches have been successfully used in vitro and in vivo (André et al., 2014; Zhu et al., 2015, 2016). However, a new direction with promising high specificity is the use of biological, customdesigned peptides, whose advantages include high potency, high specificity, relative lack of toxicity, predictable metabolism, and selective targeting of specific functions (Kaidanovich-Beilin and Eldar-Finkelman, 2006; Eldar-Finkelman and Eisenstein, 2009; Fosgerau and Hoffmann, 2015). Indeed, some peptide drugs have already been FDA approved (Kaspar and Reichert, 2013). Still, peptides suffer from disadvantages, which include instability, high susceptibility to degradation, susceptibility to hydrolysis and oxidation, tendency for aggregation, short half-life, limited bioavailability due to their low membrane permeability, and consequently, the inability to administer them orally (Fosgerau and Hoffmann, 2015). However, in recent years there have been technological developments allowing to overcome some of the drawbacks of peptides, such as conferring membrane permeability by fusion to the Tat peptide or insertion of peptides into liposomes, micelles, nano-emulsions, or polymer nanoparticles to confer membrane permeability (KaidanovichBeilin and Eldar-Finkelman, 2006). Nevertheless, this strategy is still under development.

\section{SUMMARY AND FUTURE}

As can be clearly understood from the review above, we, the authors, recognize the complexity of PKR-mediated signaling in different cells and/or body/organs at different developmental stages and cellular compartments (Figures 2, 3). The main points we conclude from the many excellent papers summarized above are:

(1) PKR level and post-translation modifications are excellent biomarkers for neurodegenerative diseases (e.g., $\mathrm{AD}$, dementia, Parkinson's disease, Huntington's disease, and prion disease) and cancer (Figure 4, based on open source data).

(2) Inhibition of PKR is predicted to be highly beneficial in age-related neurodegenerative diseases. PKR is positioned in the center of metabolic syndrome disease, including glucose or $A \beta$ load and inflammation and its inactivation reduces the insult (Figure 1).

(3) PKR inhibition contributes positively and directly to cognitive function in young and old mice.

(4) Inhibition of PKR is beneficial in certain cases of cancer. However, here, the situation is more complex as the role of PKR in tumors (pro- or anti-tumorigenic) may differ according to tumor type and/or stage.

(5) PKR inhibition or deletion is not essential for an organism response to viral infection as detected in PKR KO mice or prolonged treatments with the best-known PKR inhibitor, $\mathrm{C} 16$, and thus has the potential to serve as medical treatment.

(6) Treatment with C16 following different stimulations in most cases does not affect eIF $2 \alpha$ phosphorylation levels, although many publications are trying to explain the phenotypes of PKR inhibition via regulation of mRNA translation (Table 1 ). Moreover, brains of PKR KO mice do not show significant change in eIF $2 \alpha$ phosphorylation. On the other hand, most papers do show a clear effect of PKR inhibition on the NF- $\kappa B$ pathway (Table 1).

(7) The recent findings that PKR detects not only exogenous, viral dsRNA but also endogenous dsRNA, such as mitochondrial RNA, point to it as a new target for reducing oxidative stress and apoptosis in disease states and specifically in neurodegenerative diseases.

We hypothesize that better understanding of PKR equilibrium and function in different scenarios, in addition to its 'traditional' role in cellular viral response, can be extremely important in understanding basic related biological processes such as inflammation, metabolism, aging, cancer, and brain function in normal and pathological states. Moreover, we predict that potent, non-toxic, specific inhibition of PKR function/s will serve as treatment for different diseases in certain situations. The most plausible steps in order test our hypotheses are:

(1) Identify small molecule inhibitors for PKR. Weintraub and colleagues (2016) employed a computational chemistry screening approach, which yielded interesting but unsatisfactory results. Screening small molecule libraries is the next reasonable step.

(2) Better understanding of the interplay of levels of PKR expression, function, and cell states.

(3) Identifying new tools (i.e., non-small molecule inhibitor), such as peptides, to inhibit specific functions of PKR.

(4) Understanding the role of PKR in specific cellular and subcellular compartments (e.g., neuronal dendrites) and cellular-specific context using genetics and/or pharmacokinetic tools.

We believe that the steps proposed above together with the new tools of omics and precision biology will allow better fundamental understanding of PKR functions to be translated into treatment of currently incurable diseases.

\section{AUTHOR CONTRIBUTIONS}

All the authors contributed equally to this work. 


\section{FUNDING}

This work was supported by a grant from the Canadian Institutes of Health Research (CIHR), the International Development Research Centre (IDRC), the Israel Science Foundation (ISF) and the Azrieli Foundation (ISF-IDRC 2395/2015 to KR); ISF 946/17 to KR, Israeli Ministry of Science, Technology, and Space (MOST 3-12080 and MOST 3-14761 to KR); TransNeuro ERANET JPND

\section{REFERENCES}

Alberini, C. M., and Chen, D. Y. (2012). Memory enhancement: consolidation, reconsolidation and insulin-like growth factor 2. Trends Neurosci. 35, 274-283. doi: 10.1016/j.tins.2011.12.007

André, N. D., Silva, V. A. O., Watanabe, M. A. E., and De Lucca, F. L. (2014). Intratumoral injection of PKR shRNA expressing plasmid inhibits B16-F10 melanoma growth. Oncol. Rep. 32, 2267-2273. doi: 10.3892/or.2014.3410

Balachandran, S., Kim, C. N., Yeh, W. C., Mak, T. W., Bhalla, K., and Barber, G. N. (1998). Activation of the dsRNA-dependent protein kinase, PKR, induces apoptosis through FADD-mediated death signaling. EMBO J. 17, 6888-6902. doi: 10.1093/emboj/17.23.6888

Baltzis, D., Li, S., and Koromilas, A. E. (2002). Functional characterization of pkr gene products expressed in cells from mice with a targeted deletion of the $\mathrm{N}$ terminus or C terminus domain of PKR. J. Biol. Chem. 277, 38364-38372. doi: 10.1074/jbc.M203564200

Baltzis, D., Pluquet, O., Papadakis, A. I., Kazemi, S., Qu, L., and Koromilas, A. E. (2007). The eIF2alpha kinases PERK and PKR activate glycogen synthase kinase 3 to promote the proteasomal degradation of p53. J. Biol. Chem. 282, 31675-31687. doi: 10.1074/jbc.M704491200

Bando, Y., Onuki, R., Katayama, T., Manabe, T., Kudo, T., Taira, K., et al. (2005). Double-strand RNA dependent protein kinase (PKR) is involved in the extrastriatal degeneration in Parkinson's disease and Huntington's disease. Neurochem. Int. 46, 11-18. doi: 10.1016/j.neuint.2004.07.005

Bandyopadhyay, S. K., de La Motte, C. A., and Williams, B. R. (2000). Induction of E-selectin expression by double-stranded RNA and TNF-alpha is attenuated in murine aortic endothelial cells derived from double-stranded RNA-activated kinase (PKR)-null mice. J. Immunol. 164, 2077-2083. doi: 10.4049/jimmunol. 164.4.2077

Barber, G. N., Jagus, R., Meurs, E. F., Hovanessian, A. G., and Katze, M. G. (1995). Molecular mechanisms responsible for malignant transformation by regulatory and catalytic domain variants of the interferon-induced enzyme RNA-dependent protein kinase. J. Biol. Chem. 270, 17423-17428. doi: 10.1074/ jbc.270.29.17423

Basu, S., Panayiotidis, P., Hart, S. M., He, L. Z., Man, A., Hoffbrand, A. V., et al. (1997). Role of double-stranded RNA-activated protein kinase in human hematological malignancies. Cancer Res. 57, 943-947.

Beretta, L., Gabbay, M., Berger, R., Hanash, S. M., and Sonenberg, N. (1996). Expression of the protein kinase PKR in modulated by IRF-1 and is reduced in 5q- associated leukemias. Oncogene 12, 1593-1596.

Bomfim, T. R., Forny-Germano, L., Sathler, L. B., Brito-Moreira, J., Houzel, J., Decker, H., et al. (2012). An anti-diabetes agent protects the mouse brain from defective insulin signaling caused by Alzheimer's disease- associated A $\beta$ oligomers. J. Clin. Invest. 122, 1339-1353. doi: 10.1172/JCI57256

Bonnet, M. C., Daurat, C., Ottone, C., and Meurs, E. F. (2006). The N-terminus of PKR is responsible for the activation of the NF-kappaB signaling pathway by interacting with the IKK complex. Cell Signal. 18, 1865-1875. doi: 10.1016/j. cellsig.2006.02.010

Bonnet, M. C., Weil, R., Dam, E., Hovanessian, A. G., and Meurs, E. F. (2000). PKR stimulates NF-kappaB irrespective of its kinase function by interacting with the IkappaB kinase complex. Mol. Cell. Biol. 20, 4532-4542. doi: 10.1128/MCB.20. 13.4532-4542.2000

Bullido, M. J., Martinez-Garcia, A., Tenorio, R., Sastre, I., Munoz, D. G., Frank, A., et al. (2008). Double stranded RNA activated EIF2 alpha kinase (EIF2AK2; PKR) is associated with Alzheimer's disease. Neurobiol. Aging 29, 1160-1166. doi: 10.1016/j.neurobiolaging.2007.02.023 supported by the Israel Ministry of Health grant 3-14616 to KR; and ISF grant $1966 / 18$ to ME.

\section{ACKNOWLEDGMENTS}

The authors wish to thank Jessica Barrera for the graphic design of Figures 1-3.

Carlos, T. M., and Harlan, J. M. (1994). Leukocyte-endothelial adhesion molecules. Blood 84, 2068-2101.

Carpentier, K. S., Esparo, N. M., Child, S. J., and Geballe, A. P. (2016). A single amino acid dictates protein kinase $\mathrm{r}$ susceptibility to unrelated viral antagonists. PLoS Pathog. 12:e1005966. doi: 10.1371/journal.ppat.1005966

Carret-Rebillat, A., Pace, C., Gourmaud, S., Ravasi, L., Montagne-Stora, S., Longueville, S., et al. (2015). Neuroinflammation and A $\beta$ accumulation linked to systemic inflammation are decreased by genetic PKR down-regulation. Sci. Rep. 5:8489. doi: 10.1038/srep08489

Carvalho, B. M., Oliveira, A. G., Ueno, M., Araújo, T. G., Guadagnini, D., Carvalho-Filho, M. A., et al. (2013). Modulation of double-stranded RNAactivated protein kinase in insulin sensitive tissues of obese humans. Obesity (Silver Spring) 21, 2452-2457. doi: 10.1002/oby.20410

Carvalho-Filho, M. A., Carvalho, B. M., Oliveira, A. G., Guadagnini, D., Ueno, M., Dias, M. M., et al. (2012). Double-stranded RNA-activated protein kinase is a key modulator of insulin sensitivity in physiological conditions and in obesity in mice. Endocrinology 153, 5261-5274. doi: 10.1210/en.2012-1400

Cerami, E., Gao, J., Dogrusoz, U., Gross, B. E., Sumer, S. O., Aksoy, B. A., et al. (2012). The cBio cancer genomics portal: an open platform for exploring multidimensional cancer genomics data. Cancer Discov. 2, 401-404. doi: 10. 1158/2159-8290.CD-12-0095

Chakrabarti, A., Sadler, A. J., Kar, N., Young, H. A., Silverman, R. H., and Williams, B. R. G. (2008). Protein kinase R-dependent regulation of interleukin-10 in response to double-stranded RNA. J. Biol. Chem. 283, 25132-25139. doi: 10. 1074/jbc.M804770200

Chang, R. C., Suen, K., Ma, C., Elyaman, W., Ng, H., and Hugon, J. (2002). Involvement of double-stranded RNA-dependent protein kinase and phosphorylation of eukaryotic initiation factor-2alpha in neuronal degeneration. J. Neurochem. 83, 1215-1225. doi: 10.1046/j.1471-4159.2002. 01237.x

Chen, H., Wang, L., and D'Mello, S. R. (2008). A chemical compound commonly used to inhibit PKR, \{8-(imidazol-4-ylmethylene)-6H-azolidino[5,4-g] benzothiazol-7-one\}, protects neurons by inhibiting cyclin-dependent kinase. Eur. J. Neurosci. 28, 2003-2016. doi: 10.1111/j.1460-9568.2008. 06491.x

Cheung, B. K. W., Lee, D. C. W., Li, J. C. B., Lau, Y., and Lau, A. S. Y. (2005). A role for double-stranded RNA-activated protein kinase PKR in Mycobacterium-induced cytokine expression. J. Immunol. 175, 7218-7225. doi: 10.4049/jimmunol.175.11.7218

Chong, K. L., Feng, L., Schappert, K., Meurs, E., Donahue, T. F., Friesen, J. D., et al. (1992). Human p68 kinase exhibits growth suppression in yeast and homology to the translational regulator GCN2. EMBO J. 11, 1553-1562. doi: 10.1002/j.1460-2075.1992.tb05200.x

Costa-Mattioli, M., Gobert, D., Stern, E., Gamache, K., Colina, R., Cuello, C., et al. (2007). eIF2alpha phosphorylation bidirectionally regulates the switch from short- to long-term synaptic plasticity and memory. Cell 129, 195-206. doi: 10.1016/j.cell.2007.01.050

Coussens, L. M., and Werb, Z. (2002). Inflammation and cancer. Nature 420, 860-867. doi: 10.1038/nature01322

Couturier, J., Morel, M., Pontcharraud, R., Gontier, V., Fauconneau, B., Paccalin, M., et al. (2010). Interaction of double-stranded RNA-dependent protein kinase (PKR) with the death receptor signaling pathway in amyloid beta (Abeta)-treated cells and in APPSLPS1 knock-in mice. J. Biol. Chem. 285, 1272-1282. doi: 10.1074/jbc.M109.041954

Couturier, J., Paccalin, M., Lafay-Chebassier, C., Chalon, S., Ingrand, I., Pinguet, J., et al. (2012). Pharmacological inhibition of PKR in APPswePS1dE9 mice 
transiently prevents inflammation at 12 months of age but increases A $\beta 42$ levels in the late stages of the Alzheimer's disease. Curr. Alzheimer Res. 9, 344-360. doi: 10.2174/156720512800107582

Couturier, J., Paccalin, M., Morel, M., Terro, F., Milin, S., Pontcharraud, R., et al. (2011). Prevention of the beta-amyloid peptide-induced inflammatory process by inhibition of double-stranded RNA-dependent protein kinase in primary murine mixed co-cultures. J. Neuroinflamm. 8:72. doi: 10.1186/1742-2094-8-72

Cuddihy, A. R., Li, S., Tam, N. W., Wong, A. H., Taya, Y., Abraham, N., et al. (1999a). Double-stranded-RNA-activated protein kinase PKR enhances transcriptional activation by tumor suppressor p53. Mol. Cell. Biol. 19, 24752484. doi: 10.1128/MCB.19.4.2475

Cuddihy, A. R., Wong, A. H., Tam, N. W., Li, S., and Koromilas, A. E. (1999b). The double-stranded RNA activated protein kinase PKR physically associates with the tumor suppressor p53 protein and phosphorylates human p53 on serine 392 in vitro. Oncogene 18, 2690-2702. doi: 10.1038/sj.onc. 1202620

Dabo, S., Maillard, P., Collados Rodriguez, M., Hansen, M. D., Mazouz, S., Bigot, D., et al. (2017). Inhibition of the inflammatory response to stress by targeting interaction between PKR and its cellular activator PACT. Sci. Rep. 7:16129. doi: 10.1038/s41598-017-16089-8

Dagon, Y., Dovrat, S., Vilchik, S., Hacohen, D., Shlomo, G., Sredni, B., et al. (2001). Double-stranded RNA-dependent protein kinase, PKR, down-regulates $\mathrm{CDC} 2 /$ cyclin B1 and induces apoptosis in non-transformed but not in v-mos transformed cells. Oncogene 20, 8045-8056. doi: 10.1038/sj.onc.1204945

Danziger, O., Pupko, T., Bacharach, E., and Ehrlich, M. (2018). Interleukin-6 and interferon- $\alpha$ signaling via JAK1-STAT differentially regulate oncolytic versus cytoprotective antiviral states. Front. Immunol. 9:94. doi: 10.3389/fimmu.2018. 00094

Danziger, O., Shai, B., Sabo, Y., Bacharach, E., and Ehrlich, M. (2016). Combined genetic and epigenetic interferences with interferon signaling expose prostate cancer cells to viral infection. Oncotarget 7, 52115-52134. doi: 10.18632/ oncotarget.10313

Dar, A. C., Dever, T. E., and Sicheri, F. (2005). Higher-order substrate recognition of eIF2alpha by the RNA-dependent protein kinase PKR. Cell 122, 887-900. doi: 10.1016/j.cell.2005.06.044

De Felice, F. G., and Ferreira, S. T. (2014). Inflammation, defective insulin signaling, and mitochondrial dysfunction as common molecular denominators connecting type 2 diabetes to Alzheimer disease. Diabetes Metab. Res. Rev. 63, 2262-2272. doi: 10.2337/db13-1954

de la Monte, S. M., and Wands, J. R., (2008). Alzheimer's disease is type 3 diabetes-evidence reviewed. J. Diabetes Sci. Technol. 2, 1101-1113. doi: 10.1177/ 193229680800200619

Delgado André, N., and De Lucca, F. L. (2007). Knockdown of PKR expression by RNAi reduces pulmonary metastatic potential of B16-F10 melanoma cells in mice: possible role of NF-kappaB. Cancer Lett. 258, 118-125. doi: 10.1016/j. canlet.2007.08.021

Dey, M., Cao, C., Dar, A. C., Tamura, T., Ozato, K., Sicheri, F., et al. (2005). Mechanistic link between PKR dimerization, autophosphorylation, and eIF2alpha substrate recognition. Cell 122, 901-913. doi: 10.1016/j.cell.2005.06. 041

Dumurgier, J., Mouton-Liger, F., Lapalus, P., Prevot, M., Laplanche, J. L., Hugon, J., et al. (2013). Cerebrospinal fluid PKR level predicts cognitive decline in Alzheimer's disease. PLoS One 8:e53587. doi: 10.1371/journal.pone. 0053587

Duncan, J. W., Johnson, S., Zhang, X., Zheng, B., Luo, J., Ou, X., et al. (2016). Up-regulation of PKR signaling pathway by ethanol displays an age of onsetdependent relationship. Alcohol. Clin. Exp. Res. 40, 2320-2328. doi: 10.1111/ acer.13209

Duyckaerts, C., Delatour, B., and Potier, M. (2009). Classification and basic pathology of Alzheimer disease. Acta Neuropathol. 118, 5-36. doi: 10.1007/ s00401-009-0532-1

Dzananovic, E., McKenna, S. A., and Patel, T. R. (2018). Viral proteins targeting host protein kinase $\mathrm{R}$ to evade an innate immune response: a mini review. Biotechnol. Genet. Eng. Rev. 34, 33-59. doi: 10.1080/02648725.2018.1467151

Dzananovic, E., Patel, T. R., Chojnowski, G., Boniecki, M. J., Deo, S., McEleney, K., et al. (2014). Solution conformation of adenovirus virus associated RNA-I and its interaction with PKR. J. Struct. Biol. 185, 48-57. doi: 10.1016/j.jsb.2013. 11.007
Eldar-Finkelman, H., and Eisenstein, M. (2009). Peptide inhibitors targeting protein kinases. Curr. Pharm. Des. 15, 2463-2470. doi: 10.2174/1381612097 88682253

Elde, N. C., Child, S. J., Geballe, A. P., and Malik, H. S. (2009). Protein kinase R reveals an evolutionary model for defeating viral mimicry. Nature 457, 485-489. doi: 10.1038/nature07529

Endoh, Y., Chung, Y. M., Clark, I. A., Geczy, C. L., and Hsu, K. (2009). IL-10-dependent S100A8 gene induction in monocytes/macrophages by double-stranded RNA. J. Immunol. 182, 2258-2268. doi: 10.4049/jimmunol.08 02683

Erta, M., Quintana, A., and Hidalgo, J. (2012). Interleukin-6, a major cytokine in the central nervous system. Int. J. Biol. Sci. 8, 1254-1266. doi: 10.7150/ijbs.4679

Falletta, P., Sanchez-Del-Campo, L., Chauhan, J., Effern, M., Kenyon, A., Kershaw, C. J., et al. (2017). Translation reprogramming is an evolutionarily conserved driver of phenotypic plasticity and therapeutic resistance in melanoma. Genes Dev. 31, 18-33. doi: 10.1101/gad.290940.116

Feng, G. S., Chong, K., Kumar, A., and Williams, B. R. (1992). Identification of double-stranded RNA-binding domains in the interferon-induced doublestranded RNA-activated p68 kinase. Proc. Natl. Acad. Sci. U.S.A. 89, 5447-5451. doi: $10.1073 /$ pnas.89.12.5447

Fernandez, A. M., and Torres-Alemán, I. (2012). The many faces of insulin-like peptide signalling in the brain. Nat. Rev. Neurosci. 13, 225-239. doi: 10.1038/ nrn3209

Fosgerau, K., and Hoffmann, T. (2015). Peptide therapeutics: current status and future directions. Drug Discov. Today 20, 122-128. doi: 10.1016/j.drudis.2014. 10.003

Gal-Ben-Ari, S., Kenney, J. W., Ounalla-Saad, H., Taha, E., David, O., Levitan, D., et al. (2012). Consolidation and translation regulation. Learn. Mem. 19, 410 422. doi: 10.1101/lm.026849.112

Gao, J., Aksoy, B. A., Dogrusoz, U., Dresdner, G., Gross, B., Sumer, S. O., et al. (2013). Integrative analysis of complex cancer genomics and clinical profiles using the cBioPortal. Sci. Signal. 6:11. doi: 10.1126/scisignal.2004088

Gao, L., Tang, W., Ding, Z., Wang, D., Qi, X., Wu, H., et al. (2015). Proteinbinding function of RNA-dependent protein kinase promotes proliferation through TRAF2/RIP1/NF-кB/c-Myc pathway in pancreatic $\beta$ cells. Mol. Med. 21, 154-166.

García, M. A., Carrasco, E., Aguilera, M., Alvarez, P., Rivas, C., Campos, J. M., et al. (2011). The chemotherapeutic drug 5-fluorouracil promotes PKR-mediated apoptosis in a p53-independent manner in colon and breast cancer cells. PLoS One 6:e23887. doi: 10.1371/journal.pone.0023887

García, M. A., Meurs, E. F., and Esteban, M. (2007). The dsRNA protein kinase PKR: virus and cell control. Biochimie 89, 799-811. doi: 10.1016/j.biochi.2007. 03.001

Garcia-Ortega, M. B., Lopez, G. J., Jimenez, G., Garcia-Garcia, J. A., Conde, V., Boulaiz, H., et al. (2017). Clinical and therapeutic potential of protein kinase PKR in cancer and metabolism. Expert Rev. Mol. Med. 19:e9. doi: 10.1017/erm. 2017.11

Ghersa, P., Hooft van Huijsduijnen, R., Whelan, J., and DeLamarter, J. F. (1992). Labile proteins play a dual role in the control of endothelial leukocyte adhesion molecule-1 (ELAM-1) gene regulation. J. Biol. Chem. 267, 19226-19232.

Gil, J., and Esteban, M. (2000). Induction of apoptosis by the dsRNA-dependent protein kinase (PKR): mechanism of action. Apoptosis 5, 107-114. doi: 10.1023/ A:1009664109241

Gil, J., García, M. A., and Esteban, M. (2002). Caspase 9 activation by the dsRNAdependent protein kinase, PKR: molecular mechanism and relevance. FEBS Lett. 529, 249-255. doi: 10.1016/S0014-5793(02)03348-3

Gkogkas, C., Sonenberg, N., and Costa-Mattioli, M. (2010). Translational control mechanisms in long-lasting synaptic plasticity and memory. J. Biol. Chem. 285, 31913-31917. doi: 10.1074/jbc.R110.154476

Gregor, M. F., and Hotamisligil, G. S. (2011). Inflammatory mechanisms in obesity. Annu. Rev. Immunol. 29, 415-445. doi: 10.1146/annurev-immunol-031210101322

Grolleau, A., Kaplan, M. J., Hanash, S. M., Beretta, L., and Richardson, B. (2000). Impaired translational response and increased protein kinase PKR expression in T cells from lupus patients. J. Clin. Invest. 106, 1561-1568. doi: 10.1172/JCI9352

Haines, G. K., Panos, R. J., Bak, P. M., Brown, T., Zielinski, M., Leyland, J., et al. (1998). Interferon-responsive protein kinase (p68) and proliferating cell nuclear 
antigen are inversely distributed in head and neck squamous cell carcinoma. Tumour Biol. 19, 52-59. doi: 10.1159/000029974

Hanahan, D., and Weinberg, R. A. (2011). Hallmarks of cancer: the next generation. Cell 144, 646-674. doi: 10.1016/j.cell.2011.02.013

Hii, S. I., Hardy, L., Crough, T., Payne, E. J., Grimmett, K., Gill, D., et al. (2004). Loss of PKR activity in chronic lymphocytic leukemia. Int. J. Cancer 109, 329-335. doi: $10.1002 /$ ijc. 11714

Hoang, H., Graber, T. E., and Alain, T. (2018). Battling for ribosomes: translational control at the forefront of the antiviral response. J. Mol. Biol. 430, 1965-1992. doi: 10.1016/j.jmb.2018.04.040

Hopkins, S. J., and Rothwell, N. J. (1995). Cytokines and the nervous system. I: Expression and recognition. Trends Neurosci. 18, 83-88.

$\mathrm{Hu}, \mathrm{Y}$. , and Conway, T. W. (1993). 2-Aminopurine inhibits the double-stranded RNA-dependent protein kinase both in vitro and in vivo. J. Interferon Res. 13, 323-328. doi: 10.1089/jir.1993.13.323

Hu, Z., Zhang, H., Tang, L., Lou, M., and Geng, Y. (2017). Silencing nc886, a noncoding RNA, induces apoptosis of human endometrial cancer cells-1A in vitro. Med. Sci. Monit. 23, 1317-1324. doi: 10.12659/MSM.900320

Hugon, J., Mouton-Liger, F., Dumurgier, J., and Paquet, C. (2017). PKR involvement in Alzheimer's disease. Alzheimers Res. Ther. 9:83. doi: 10.1186/ s13195-017-0308-0

Hugon, J., Paquet, C., and Chang, R. C. (2009). Could PKR inhibition modulate human neurodegeneration? Exp. Rev. Neurother 9, 1455-1457. doi: 10.1586/ ern.09.92

Hummer, B. T., Li, X. L., and Hassel, B. A. (2001). Role for p53 in gene induction by double-stranded RNA. J. Virol. 75, 7774-7777. doi: 10.1128/JVI.75.16.77747777.2001

Hwang, K., Bak, M. S., Kim, S. J., Rhee, S., and Lee, Y. (2017). Restoring synaptic plasticity and memory in mouse models of Alzheimer's disease by PKR inhibition. Mol. Brain 10:57. doi: 10.1186/s13041-017-0338-3

Ingrand, S., Barrier, L., Lafay-Chebassier, C., Fauconneau, B., Page, G., and Hugon, J. (2007). The oxindole/imidazole derivative $\mathrm{C} 16$ reduces in vivo brain PKR activation. FEBS Lett. 581, 4473-4478. doi: 10.1016/j.febslet.2007. 08.022

Jagus, R., Joshi, B., and Barber, G. N. (1999). PKR, apoptosis and cancer. Int. J. Biochem. Cell Biol. 31, 123-138. doi: 10.1016/S1357-2725(98)00136-8

Jammi, N. V., Whitby, L. R., and Beal, P. A. (2003). Small molecule inhibitors of the RNA-dependent protein kinase. Biochem. Biophys. Res. Commun. 308, 50-57. doi: 10.1016/S0006-291X(03)01318-4

Jiang, Z., Belforte, J. E., Lu, Y., Yabe, Y., Pickel, J., Smith, C. B., et al. (2010). eIF $2 \alpha$ Phosphorylation-dependent translation in CA1 pyramidal cells impairs hippocampal memory consolidation without affecting general translation. $J$. Neurosci. 30, 2582-2594. doi: 10.1523/JNEUROSCI.3971-09.2010

Jiang, Z., Zamanian-Daryoush, M., Nie, H., Silva, A. M., Williams, B. R. G., and Li, X. (2003). Poly(I-C)-induced Toll-like receptor 3 (TLR3)-mediated activation of NFkappa B and MAP kinase is through an interleukin-1 receptorassociated kinase (IRAK)-independent pathway employing the signaling components TLR3-TRAF6-TAK1-TAB2-PKR. J. Biol. Chem. 278, 16713-16719. doi: 10.1074/jbc.M300562200

Kadereit, S., Xu, H., Engeman, T. M., Yang, Y. L., Fairchild, R. L., and Williams, B. R. (2000). Negative regulation of CD8+ T cell function by the IFN-induced and double-stranded RNA-activated kinase PKR. J. Immunol. 165, 6896-6901. doi: 10.4049/jimmunol.165.12.6896

Kadokami, T., Frye, C., Lemster, B., Wagner, C. L., Feldman, A. M., and McTiernan, C. F. (2001). Anti-tumor necrosis factor-alpha antibody limits heart failure in a transgenic model. Circulation 104, 1094-1097. doi: 10.1161/hc3501. 096063

Kahn, M. S., Kranjac, D., Alonzo, C. A., Haase, J. H., Cedillos, R. O., McLinden, K. A., et al. (2012). Prolonged elevation in hippocampal A $\beta$ and cognitive deficits following repeated endotoxin exposure in the mouse. Behav. Brain Res. 229, 176-184. doi: 10.1016/j.bbr.2012.01.010

Kaidanovich-Beilin, O., and Eldar-Finkelman, H. (2006). Peptides targeting protein kinases: strategies and implications. Physiology (Bethesda) 21, 411-418. doi: 10.1152/physiol.00022.2006

Kalra, J., Mangali, S. B., Bhat, A., Dhar, I., Udumula, M. P., and Dhar, A. (2018). Imoxin attenuates high fructose-induced oxidative stress and apoptosis in renal epithelial cells via downregulation of protein kinase R pathway. Fundam. Clin. Pharmacol. 32, 297-305. doi: 10.1111/fcp. 12352
Kapil, P., Stohlman, S. A., Hinton, D. R., and Bergmann, C. C. (2014). PKR mediated regulation of inflammation and IL-10 during viral encephalomyelitis. J. Neuroimmunol. 270, 1-12. doi: 10.1016/j.jneuroim.2014.02.012

Kaspar, A. A., and Reichert, J. M. (2013). Future directions for peptide therapeutics development. Drug Discov. Today 18, 807-817. doi: 10.1016/j.drudis.2013. 05.011

Khandelwal, P. J., Herman, A. M., and Moussa, C. E. (2011). Inflammation in the early stages of neurodegenerative pathology. J. Neuroimmunol. 238, 1-11. doi: 10.1016/j.jneuroim.2011.07.002

Kim, S. H., Forman, A. P., Mathews, M. B., and Gunnery, S. (2000). Human breast cancer cells contain elevated levels and activity of the protein kinase. PKR Oncogene 19, 3086-3094. doi: 10.1038/sj.onc.1203632

Kim, S. H., Gunnery, S., Choe, J. K., and Mathews, M. B. (2002). Neoplastic progression in melanoma and colon cancer is associated with increased expression and activity of the interferon-inducible protein kinase. $P K R$ Oncogene 21, 8741-8748. doi: 10.1038/sj.onc. 1205987

Kim, Y., Lee, J. H., Park, J., Cho, J., Yi, H., and Kim, V. N. (2014). PKR is activated by cellular dsRNAs during mitosis and acts as a mitotic regulator. Genes Dev. 28, 1310-1322. doi: 10.1101/gad.242644.114

Kim, Y., Park, J., Kim, S., Kim, M., Kim, M., Kang, M. G., Kwak, C., et al. (2018). PKR senses nuclear and mitochondrial signals by interacting with endogenous double-stranded RNAs. Mol. Cell. 71, 1051.e6-1063.e6 doi: 10.1016/j.molcel. 2018.07.029

Klann, E., and Richter, J. D. (2007). "Translational control of synaptic plasticity and learning and memory," in eds Translational Control in Biology and Medicine, eds N. Sonenberg, J. W. B. Hershey, and M. B. Matthews (Cold Spring Harbor, NY: Cold Spring Harbor Laboratory Press), 485-506

Koromilas, A. E., Roy, S., Barber, G. N., Katze, M. G., and Sonenberg, N. (1992). Malignant transformation by a mutant of the IFN-inducible dsRNA-dependent protein kinase. Science 257, 1685-1689. doi: 10.1126/science.1382315

Krstic, D., Madhusudan, A., Doehner, J., Vogel, P., Notter, T., Imhof, C., et al. (2012). Systemic immune challenges trigger and drive Alzheimer-like neuropathology in mice. J. Neuroinflamm. 9:151. doi: 10.1186/1742-20949-151

Kuhen, K. L., and Samuel, C. E. (1997). Isolation of the interferon-inducible RNAdependent protein kinase $\mathrm{Pkr}$ promoter and identification of a novel DNA element within the 5'-flanking region of human and mouse Pkr genes. Virology 227, 119-130. doi: 10.1006/viro.1996.8306

Kumar, A., Haque, J., Lacoste, J., Hiscott, J., and Williams, B. R. (1994). Doublestranded RNA-dependent protein kinase activates transcription factor NFkappa B by phosphorylating I kappa B. Proc. Natl. Acad. Sci. U.S.A. 91, 6288-6292. doi: 10.1073/pnas.91.14.6288

Lancaster, G. I., Kammoun, H. L., Kraakman, M. J., Kowalski, G. M., Bruce, C. R., and Febbraio, M. A. (2016). PKR is not obligatory for high-fat diet-induced obesity and its associated metabolic and inflammatory complications. Nat. Commun. 7:10626. doi: 10.1038/ncomms10626

Lee, E. K., Hong, S., Shin, S., Lee, H., Lee, J., Park, E. J., et al. (2016). nc886, a noncoding RNA and suppressor of PKR, exerts an oncogenic function in thyroid cancer. Oncotarget 7, 75000-75012. doi: 10.18632/oncotarget.11852

Lee, H., Lee, K., Jang, H., Lee, G. K., Park, J., Kim, S. Y., et al. (2014). Epigenetic silencing of the non-coding RNA nc886 provokes oncogenes during human esophageal tumorigenesis. Oncotarget 5, 3472-3481. doi: 10.18632/oncotarget. 1927

Lee, K., Kunkeaw, N., Jeon, S. H., Lee, I., Johnson, B. H., Kang, G., et al. (2011). Precursor miR-886, a novel noncoding RNA repressed in cancer, associates with PKR and modulates its activity. RNA 17, 1076-1089. doi: 10.1261/rna.27 01111

Li, G., Scull, C., Ozcan, L., and Tabas, I. (2010). NADPH oxidase links endoplasmic reticulum stress, oxidative stress, and PKR activation to induce apoptosis. J. Cell Biol. 191, 1113-1125. doi: 10.1083/jcb.201006121

Li, S., Peters, G. A., Ding, K., Zhang, X., Qin, J., and Sen, G. C. (2006). Molecular basis for PKR activation by PACT or dsRNA. Proc. Natl. Acad. Sci. U.S.A. 103, 10005-10010. doi: 10.1073/pnas.0602317103

Li, W. H., Tanimura, M., Luo, C. C., Datta, S., and Chan, L. (1988). The apolipoprotein multigene family: biosynthesis, structure, structure-function relationships and evolution. J. Lipid Res. 29, 245-271.

Li, Y., Xiao, J., Tan, Y., Wang, J., Zhang, Y., Deng, X., et al. (2017). Inhibition of PKR ameliorates lipopolysaccharide-induced acute lung injury by suppressing 
NF-кB pathway in mice. Immunopharmacol. Immunotoxicol. 39, 165-172. doi: 10.1080/08923973.2017.1303839

Li, Y., Peng Zhou, Y., Wang, C., Li, L., Leng, Y., Chen, R., et al. (2018). Novel role of PKR in palmitate-induced Sirtl inactivation and endothelial cell senescence. Am. J. Physiol. Heart Circ. Physiol. 315, H571-H580. doi: 10.1152/ajpheart. 00038.2018

Liu, G., and Zhang, W. (2018). Long non-coding RNA HOTAIR promotes UVB-induced apoptosis and inflammatory injury by up-regulation of PKR in keratinocytes. Braz. J. Med. Biol. Res. 51:e6896. doi: 10.1590/1414$431 \times 20186896$

Lourenco, M. V., Clarke, J. R., Frozza, R. L., Bomfim, T. R., Forny-Germano, L., Batista, A. F., et al. (2013). TNF-alpha mediates PKR-dependent memory impairment and brain IRS-1 inhibition induced by Alzheimer's beta-amyloid oligomers in mice and monkeys. Cell. Metab. 18, 831-843. doi: 10.1016/j.cmet. 2013.11.002

Lu, B., Nakamura, T., Inouye, K., Li, J., Tang, Y., Lundbäck, P., et al. (2012). Novel role of PKR in inflammasome activation and HMGB1 release. Nature 488, 670-674. doi: 10.1038/nature 11290

Lu, Z., Xu, X., Hu, X., Lee, S., Traverse, J. H., Zhu, G., et al. (2010). Oxidative stress regulates left ventricular PDE5 expression in the failing heart. Circulation 121, 1474-1483. doi: 10.1161/CIRCULATIONAHA.109.906818

Ma, T., Trinh, M. A., Wexler, A. J., Bourbon, C., Gatti, E., Pierre, P., et al. (2013). Suppression of eIF2 $\alpha$ kinases alleviates Alzheimer's disease-related plasticity and memory deficits. Nat. Neurosci. 2013, 1299-1305. doi: 10.1038/nn.3486

Maran, A., Maitra, R. K., Kumar, A., Dong, B., Xiao, W., Li, G., et al. (1994). Blockage of NF-kappa B signaling by selective ablation of an mRNA target by 2-5A antisense chimeras. Science 265, 789-792. doi: 10.1126/science.7914032

Marchal, J. A., Carrasco, E., Ramirez, A., Jiménez, G., Olmedo, C., Peran, M., et al. (2013). Bozepinib, a novel small antitumor agent, induces PKR-mediated apoptosis and synergizes with IFN $\alpha$ triggering apoptosis, autophagy and senescence. Drug Des. Dev. Ther. 7, 1301-1313.

Marques, J. T., Rebouillat, D., Ramana, C. V., Murakami, J., Hill, J. E., Gudkov, A., et al. (2005). Down-regulation of p53 by double-stranded RNA modulates the antiviral response. J. Virol. 79, 11105-11114. doi: 10.1128/JVI.79.17.1110511114.2005

McAllister, C. S., Taghavi, N., and Samuel, C. E. (2012). Protein kinase PKR amplification of interferon $\beta$ induction occurs through initiation factor eIF$2 \alpha$-mediated translational control. J. Biol. Chem. 287, 36384-36392. doi: 10. 1074/jbc.M112.390039

McKenna, S. A., Kim, I., Liu, C. W., and Puglisi, J. D. (2006). Uncoupling of RNA binding and PKR kinase activation by viral inhibitor RNAs. J. Mol. Biol. 358, 1270-1285. doi: 10.1016/j.jmb.2006.03.003

Meurs, E., Chong, K., Galabru, J., Thomas, N. S., Kerr, I. M., Williams, B. R., et al. (1990). Molecular cloning and characterization of the human doublestranded RNA-activated protein kinase induced by interferon. Cell 62, 379-390. doi: 10.1016/0092-8674(90)90374-N

Meurs, E. F., Galabru, J., Barber, G. N., Katze, M. G., and Hovanessian, A. G. (1993). Tumor suppressor function of the interferon-induced double-stranded RNA-activated protein kinase. Proc. Natl. Acad. Sci. U.S.A. 90, 232-236. doi: 10.1073/pnas.90.1.232

Monteiro, S., Ferreira, F. M., Pinto, V., Roque, S., Morais, M., de SáCalçada, D., et al. (2016). Absence of IFN $\gamma$ promotes hippocampal plasticity and enhances cognitive performance. Transl. Psychiatry 6:e707. doi: 10.1038/tp. 2015.194

Mouton-Liger, F., Paquet, C., Dumurgier, J., Lapalus, P., Gray, F., Laplanche, J. L., et al. (2012). Increased cerebrospinal fluid levels of double-stranded RNAdependant protein kinase in Alzheimer's disease. Biol. Psychiatry 71, 829-835. doi: 10.1016/j.biopsych.2011.11.031

Nakamura, T., Arduini, A., Baccaro, B., Furuhashi, M., and Hotamisligil, G. S. (2014). Small-molecule inhibitors of PKR improve glucose homeostasis in obese diabetic mice. Diabetes Metab. Res. Rev. 63, 526-534. doi: 10.2337/db131019

Nakamura, T., Furuhashi, M., Li, P., Cao, H., Tuncman, G., Sonenberg, N., et al. (2010). Double-stranded RNA-dependent protein kinase links pathogen sensing with stress and metabolic homeostasis. Cell 140, 338-348. doi: 10.1016/ j.cell.2010.01.001

Nakamura, T., Kunz, R. C., Zhang, C., Kimura, T., Yuan, C. L., Baccaro, B., et al. (2015). A critical role for PKR complexes with TRBP in immunometabolic regulation and eIF $2 \alpha$ phosphorylation in obesity. Cell Rep. 11, 295-307. doi: 10.1016/j.celrep.2015.03.021

Osborn, L. (1990). Leukocyte adhesion to endothelium in inflammation. Cell 62, 3-6. doi: 10.1016/0092-8674(90)90230-C

Ounallah-Saad, H., Sharma, V., Edry, E., and Rosenblum, K. (2014). Genetic or pharmacological reduction of PERK enhances cortical-dependent taste learning. J. Neurosci. 34, 14624-14632. doi: 10.1523/JNEUROSCI.2117-14. 2014

Paccalin, M., Pain-Barc, S., Pluchon, C., Paul, C., Besson, M., Carret-Rebillat, A., et al. (2006). Activated mTOR and PKR kinases in lymphocytes correlate with memory and cognitive decline in Alzheimer's disease. Dement. Geriatr. Cogn. Disord. 22, 320-326. doi: 10.1159/000095562

Papadakis, A. I., Paraskeva, E., Peidis, P., Muaddi, H., Li, S., Raptis, L., et al. (2010). eIF2\{alpha\} Kinase PKR modulates the hypoxic response by Stat3-dependent transcriptional suppression of HIF-1\{alpha\}. Cancer Res. 70, 7820-7829. doi: 10.1158/0008-5472.CAN-10-0215

Peel, A. L., and Bredesen, D. E. (2003). Activation of the cell stress kinase PKR in Alzheimer's disease and human amyloid precursor protein transgenic mice. Neurobiol. Dis. 14, 52-62. doi: 10.1016/S0969-9961(03)00086-X

Peel, A. L., Rao, R. V., Cottrell, B. A., Hayden, M. R., Ellerby, L. M., and Bredesen, D. E. (2001). Double-stranded RNA-dependent protein kinase, PKR, binds preferentially to Huntington's disease (HD) transcripts and is activated in HD tissue. Hum. Mol. Genet. 10, 1531-1538. doi: 10.1093/hmg/10.15.1531

Peidis, P., Papadakis, A. I., Muaddi, H., Richard, S., and Koromilas, A. E. (2011). Doxorubicin bypasses the cytoprotective effects of eIF $2 \alpha$ phosphorylation and promotes PKR-mediated cell death. Cell Death. Differ. 18, 145-154. doi: 10. 1038/cdd.2010.76

Peidis, P., Papadakis, A. I., Rajesh, K., and Koromilas, A. E. (2010). HDAC pharmacological inhibition promotes cell death through the eIF $2 \alpha$ kinases PKR and GCN2. Aging (Albany NY) 2, 669-677. doi: 10.18632/aging.100216

Pikarsky, E., and Ben-Neriah, Y. (2006). NF-kappaB inhibition: a double-edged sword in cancer? Eur. J. Cancer 42, 779-784. doi: 10.1016/j.ejca.2006.01.011

Qi, Y., Zhang, M., Li, H., Frank, J. A., Dai, L., Liu, H., et al. (2014). MicroRNA$29 \mathrm{~b}$ regulates ethanol-induced neuronal apoptosis in the developing cerebellum through SP1/RAX/PKR cascade. J. Biol. Chem. 289, 10201-10210. doi: 10.1074/ jbc.M113.535195

Rosenblum, K., Meiri, N., and Dudai, Y. (1993). Taste memory: the role of protein synthesis in gustatory cortex. Behav. Neural Biol. 59, 49-56. doi: 10.1016/01631047(93)91145-D

Rothenburg, S., Seo, E. J., Gibbs, J. S., Dever, T. E., and Dittmar, K. (2009). Rapid evolution of protein kinase PKR alters sensitivity to viral inhibitors. Nat. Struct. Mol. Biol. 16, 63-70. doi: 10.1038/nsmb.1529

Rouillard, A. D., Gundersen, G. W., Fernandez, N. F., Wang, Z., Monteiro, C. D., McDermott, M. G., et al. (2016). The harmonizome: a collection of processed datasets gathered to serve and mine knowledge about genes and proteins. Database (Oxford) 3:2016. doi: 10.1093/database/baw100

Schindler, U., and Baichwal, V. R. (1994). Three NF-kappa B binding sites in the human E-selectin gene required for maximal tumor necrosis factor alphainduced expression. Mol. Cell. Biol. 14, 5820-5831. doi: 10.1128/MCB.14.9. 5820

Schulz, O., Pichlmair, A., Rehwinkel, J., Rogers, N. C., Scheuner, D., Kato, H., et al. (2010). Protein kinase R contributes to immunity against specific viruses by regulating interferon mRNA integrity. Cell. Host. Microbe. 7, 354-361. doi: 10.1016/j.chom.2010.04.007

Segev, Y., Barrera, I., Ounallah-Saad, H., Wibrand, K., Sporild, I., Livne, A., et al. (2015). PKR inhibition rescues memory deficit and ATF4 overexpression in ApoE epsilon4 human replacement mice. J. Neurosci. 35, 12986-1299.3 doi: 10.1523/JNEUROSCI.5241-14.2015

Segev, Y., Livne, A., Mints, M., and Rosenblum, K. (2016). Concurrence of high fat diet and APOE gene induces allele specific metabolic and mental stress changes in a mouse model of Alzheimer's disease. Front. Behav. Neurosci. 10:170. doi: 10.3389/fnbeh.2016.00170

Segev, Y., Michaelson, D. M., and Rosenblum, K. (2013). ApoE epsilon4 is associated with eIF2alpha phosphorylation and impaired learning in young mice. Neurobiol. Aging 34, 863-872. doi: 10.1016/j.neurobiolaging.2012.06.020

Sharma, P., Hu-Lieskovan, S., Wargo, J. A., and Ribas, A. (2017). Primary, adaptive, and acquired resistance to cancer immunotherapy. Cell 168, 707-723. doi: 10.1016/j.cell.2017.01.017 
Sharma, V., Ounallah-Saad, H., Chakraborty, D., Hleihil, M., Sood, R., Barrera, I., et al. (2018). Local inhibition of PERK enhances memory and reverses agerelated deterioration of cognitive and neuronal properties. J. Neurosci. 38, 648-658. doi: 10.1523/JNEUROSCI.0628-17.2017

Shen, S., Niso-Santano, M., Adjemian, S., Takehara, T., Malik, S. A., Minoux, H., et al. (2012). Cytoplasmic STAT3 represses autophagy by inhibiting PKR activity. Mol. Cell 48, 667-680. doi: 10.1016/j.molcel.2012.09.013

Song, Y., Wan, X., Gao, L., Pan, Y., Xie, W., Wang, H., et al. (2015). Activated PKR inhibits pancreatic $\beta$-cell proliferation through sumoylation-dependent stabilization of P53. Mol. Immunol. 68, 341-349. doi: 10.1016/j.molimm.2015. 09.007

Stern, E., Chinnakkaruppan, A., David, O., Sonenberg, N., and Rosenblum, K. (2013). Blocking the eIF2alpha kinase (PKR) enhances positive and negative forms of cortex-dependent taste memory. J. Neurosci. 33, 2517-2525. doi: 10. 1523/JNEUROSCI.2322-12.2013

Stojdl, D. F., Lichty, B., Knowles, S., Marius, R., Atkins, H., Sonenberg, N., et al. (2000). Exploiting tumor-specific defects in the interferon pathway with a previously unknown oncolytic virus. Nat. Med. 6, 821-825. doi: 10.1038/ 77558

Strong, J. E., Coffey, M. C., Tang, D., Sabinin, P., and Lee, P. W. (1998). The molecular basis of viral oncolysis: usurpation of the Ras signaling pathway by reovirus. EMBO J. 17, 3351-3362. doi: 10.1093/emboj/17.12.3351

Swetha, M., and Ramaiah, K. V. A. (2015). Insulin treatment promotes tyrosine phosphorylation of PKR and inhibits polyIC induced PKR threonine phosphorylation. Arch. Biochem. Biophys. 585, 98-108. doi: 10.1016/j.abb.2015. 07.012

Taga, M., Minett, T., Classey, J., Matthews, F. E., Brayne, C., Ince, P. G., et al. (2017). Metaflammasome components in the human brain: a role in dementia with Alzheimer's pathology? Brain Pathol. 27, 266-275. doi: 10.1111/bpa.12388

Taga, M., Mouton-Liger, F., Sadoune, M., Gourmaud, S., Norman, J., Tible, M., et al. (2018). PKR modulates abnormal brain signaling in experimental obesity. PLoS One 13:e0196983. doi: 10.1371/journal.pone.0196983

Takaoka, A., Hayakawa, S., Yanai, H., Stoiber, D., Negishi, H., Kikuchi, H., et al. (2003). Integration of interferon-alpha/beta signalling to p53 responses in tumour suppression and antiviral defence. Nature 424, 516-523. doi: 10.1038/ nature 01850

Taniguchi, K., and Karin, M. (2018). NF-кB, inflammation, immunity and cancer: coming of age. Nat. Rev. Immunol. 18, 309-324. doi: 10.1038/nri.2017.142

Taniuchi, S., Miyake, M., Tsugawa, K., Oyadomari, M., and Oyadomari, S. (2016). Integrated stress response of vertebrates is regulated by four eIF $2 \alpha$ kinases. Sci. Rep. 6:32886. doi: 10.1038/srep32886

Taylor, D. R., Tian, B., Romano, P. R., Hinnebusch, A. G., Lai, M. M., and Mathews, M. B. (2001). Hepatitis C virus envelope protein E2 does not inhibit PKR by simple competition with autophosphorylation sites in the RNA-binding domain. J. Virol. 75, 1265-1273. doi: 10.1128/JVI.75.3.1265-1273.2001

Trinh, M. A., Kaphzan, H., Wek, R. C., Pierre, P., Cavener, D. R., and Klann, E. (2012). Brain-specific disruption of the eIF2alpha kinase PERK decreases ATF4 expression and impairs behavioral flexibility. Cell Rep. 1, 676-688. doi: 10.1016/ j.celrep.2012.04.010

Trinh, M. A., Ma, T., Kaphzan, H., Bhattacharya, A., Antion, M. D., Cavener, D. R., et al. (2014). The eIF2alpha kinase PERK limits the expression of hippocampal metabotropic glutamate receptor-dependent long-term depression. Learn. Mem. 21, 298-304. doi: 10.1101/lm.032219.113

Tronel, C., Page, G., Bodard, S., Chalon, S., and Antier, D. (2014). The specific PKR inhibitor $\mathrm{C} 16$ prevents apoptosis and IL- $1 \beta$ production in an acute excitotoxic rat model with a neuroinflammatory component. Neurochem. Int. 64, 73-83. doi: 10.1016/j.neuint.2013.10.012

Udumula, M. P., Babu, M. S., Bhat, A., Dhar, I., Sriram, D., and Dhar, A. (2017). High glucose impairs insulin signaling via activation of PKR pathway in L6 muscle cells. Biochem. Biophys. Res. Commun. 486, 645-651. doi: 10.1016/j.bbrc. 2017.03.078

Udumula, M. P., Bhat, A., Mangali, S., Kalra, J., Dhar, I., Sriram, D., et al. (2018). Pharmacological evaluation of novel PKR inhibitor indirubin-3-hydrazone invitro in cardiac myocytes and in-vivo in wistar rats. Life Sci. 209, 85-96. doi: 10.1016/j.lfs.2018.07.055

Volonte, D., Zou, H., Bartholomew, J. N., Liu, Z., Morel, P. A., and Galbiati, F. (2015). Oxidative stress-induced inhibition of Sirt1 by caveolin-1 promotes p53-dependent premature senescence and stimulates the secretion of interleukin 6 (IL-6). J. Biol. Chem. 290, 4202-4214. doi: 10.1074/jbc.M114. 598268

von Roretz, C., and Gallouzi, I. (2010). Protein kinase RNA/FADD/caspase-8 pathway mediates the proapoptotic activity of the RNA-binding protein human antigen R (HuR). J. Biol. Chem. 285, 16806-16813. doi: 10.1074/jbc.M109. 087320

Wahid, A. M., Coventry, V. K., and Conn, G. L. (2009). The PKR-binding domain of adenovirus VA RNAI exists as a mixture of two functionally non-equivalent structures. Nucleic Acids Res. 37, 5830-5837. doi: 10.1093/nar/gkp595

Wang, H., Xu, X., Fassett, J., Kwak, D., Liu, X., Hu, X., et al. (2014). Doublestranded RNA-dependent protein kinase deficiency protects the heart from systolic overload-induced congestive heart failure. Circulation 129, 1397-1406. doi: 10.1161/CIRCULATIONAHA.113.002209

Wang, W. J., Yin, S. J., and Rong, R. Q. (2015). PKR and HMGB1 expression and function in rheumatoid arthritis. Genet. Mol. Res. 14, 17864-17870. doi: 10.4238/2015.December.22.11

Wang, X., Fan, Z., Wang, B., Luo, J., and Ke, Z. (2007). Activation of doublestranded RNA-activated protein kinase by mild impairment of oxidative metabolism in neurons. J. Neurochem. 103, 2380-2390. doi: 10.1111/j.14714159.2007.04978.x

Ward, A., Crean, S., Mercaldi, C. J., Collins, J. M., Boyd, D., Cook, M. N., et al. (2012). Prevalence of apolipoprotein E4 genotype and homozygotes (APOE e4/4) among patients diagnosed with Alzheimer's disease: a systematic review and meta-analysis. Neuroepidemiology 38, 1-17. doi: 10.1159/000334607

Watanabe, T., Imamura, T., and Hiasa, Y. (2018). Roles of protein kinase R in cancer: potential as a therapeutic target. Cancer Sci. 109, 919-925. doi: 10.1111/ cas. 13551

Webster, S. J., Ellis, L., O’Brien, L. M., Tyrrell, B., Fitzmaurice, T. J., Elder, M. J., et al. (2016). IRE1 $\alpha$ mediates PKR activation in response to Chlamydia trachomatis infection. Microbes Infect. 18, 472-483. doi: 10.1016/j.micinf.2016. 03.010

Weintraub, S., Yarnitzky, T., Kahremany, S., Barrera, I., Viskind, O., Rosenblum, K., et al. (2016). Design and synthesis of novel protein kinase R (PKR) inhibitors. Mol. Divers. 20, 805-819. doi: 10.1007/s11030-016-9689-4

Xiao, J., Tan, Y., Li, Y., and Luo, Y. (2016). The specific protein kinase R (PKR) inhibitor $\mathrm{C} 16$ protects neonatal hypoxia-ischemia brain damages by inhibiting neuroinflammation in a neonatal rat model. Med. Sci. Monit. 22, 5074-5081. doi: 10.12659/MSM.898139

Yang, W., Zhou, X., Zimmermann, H. R., Cavener, D. R., Klann, E., and Ma, T. (2016). Repression of the eIF2 $\alpha$ kinase PERK alleviates mGluR-LTD impairments in a mouse model of Alzheimer's disease. Neurobiol. Aging 41, 19-24. doi: 10.1016/j.neurobiolaging.2016.02.005

Yoon, C., Lee, E., Lim, D., and Bae, Y. (2009). PKR, a p53 target gene, plays a crucial role in the tumor-suppressor function of p53. Proc. Natl. Acad. Sci. U.S.A. 106, 7852-7857. doi: 10.1073/pnas.0812148106

Yoon, C., Miah, M. A., Kim, K. P., and Bae, Y. (2010). New Cdc2 Tyr 4 phosphorylation by dsRNA-activated protein kinase triggers Cdc2 polyubiquitination and G2 arrest under genotoxic stresses. EMBO Rep. 11, 393-399. doi: 10.1038/embor.2010.45

Youssef, O. A., Safran, S. A., Nakamura, T., Nix, D. A., Hotamisligil, G. S., and Bass, B. L. (2015). Potential role for snoRNAs in PKR activation during metabolic stress. Proc. Natl. Acad. Sci. U.S.A. 112, 5023-5028. doi: 10.1073/pnas. 1424044112

Zamanian-Daryoush, M., Der, S. D., and Williams, B. R. (1999). Cell cycle regulation of the double stranded RNA activated protein kinase. PKR Oncogene 18, 315-326. doi: 10.1038/sj.onc. 1202293

Zaretsky, J. M., Garcia-Diaz, A., Shin, D. S., Escuin-Ordinas, H., Hugo, W., HuLieskovan, S., et al. (2016). Mutations associated with acquired resistance to PD-1 blockade in melanoma. N. Engl. J. Med. 375, 819-829. doi: 10.1056/ NEJMoa1604958

Zhang, J. S., Zhou, S. F., Wang, Q., Guo, J. N., Liang, H. M., Deng, J. B., et al. (2016). Gastrodin suppresses BACE1 expression under oxidative stress condition via inhibition of the PKR/eIF2 $\alpha$ pathway in Alzheimer's disease. Neuroscience 325, 1-9. doi: 10.1016/j.neuroscience.2016.03.024

Zhang, P., and Samuel, C. E. (2008). Induction of protein kinase PKR-dependent activation of interferon regulatory factor 3 by vaccinia virus occurs through adapter IPS-1 signaling. J. Biol. Chem. 283, 34580-34587. doi: 10.1074/jbc. M807029200 
Zhu, M., Liu, X., Wang, S., Miao, J., Wu, L., Yang, X., et al. (2016). PKR promotes choroidal neovascularization via upregulating the PI3K/Akt signaling pathway in VEGF expression. Mol. Vis. 22, 1361-1374.

Zhu, P. J., Huang, W., Kalikulov, D., Yoo, J. W., Placzek, A. N., Stoica, L., et al. (2011). Suppression of PKR promotes network excitability and enhanced cognition by interferon-gamma-mediated disinhibition. Cell 147, 1384-1396. doi: 10.1016/j.cell.2011.11.029

Zhu, Z., Zhong, H., Zhou, Q., Hu, X., Chen, D., Wang, J., et al. (2015). Inhibition of PKR impairs angiogenesis through a VEGF pathway. Am. J. Physiol. Endocrinol. Metab. 308, 518. doi: 10.1152/ajpendo.00469.2014

Zimmermann, H. R., Yang, W., Beckelman, B. C., Kasica, N. P., Zhou, X., Galli, L. D., et al. (2018). Genetic removal of eIF2 $\alpha$ kinase PERK in mice enables hippocampal L-LTP independent of mTORC1 activity. J. Neurochem. 146, 133-144. doi: 10.1111/jnc.14306
Conflict of Interest Statement: KR serves as Chief Scientific Officer at Protekt Therapeutics Ltd.

The remaining authors declare that the research was conducted in the absence of any commercial or financial relationships that could be construed as a potential conflict of interest.

Copyright $(2019$ Gal-Ben-Ari, Barrera, Ehrlich and Rosenblum. This is an openaccess article distributed under the terms of the Creative Commons Attribution License (CC BY). The use, distribution or reproduction in other forums is permitted, provided the original author(s) and the copyright owner(s) are credited and that the original publication in this journal is cited, in accordance with accepted academic practice. No use, distribution or reproduction is permitted which does not comply with these terms. 